\title{
菲并咪唑类衍生物蓝光材料的研究进展
}

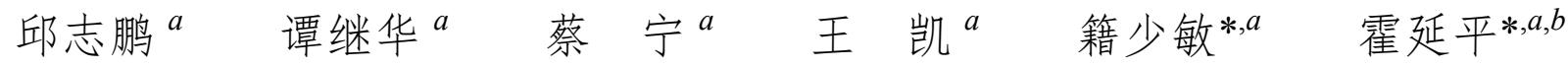 \\ $\left({ }^{a}\right.$ 广东工业大学轻工化工学院 广州 510006) \\ ${ }^{b}$ 中国科学院上海有机化学研究所 有机氟化学中国科学院重点实验室 上海 200032)
}

\begin{abstract}
摘要 即将出现的全球能源危机和低效的能源利用推动了节能设备在显示和照明领域中的应用. 节能的有机发光二极 管被认为是新一代智能显示器, 成为未来节能照明光源最具竞争力的候选产品之一. 而高效深蓝色材料的分子设计由 于其固有的宽带隙, 载流子电荷传输不平衡以及其在固态下的低效率, 发展受到很大限制. 菲并咪唑基团作为一种新 型蓝光材料的构筑单元, 具吸引力的双极特性和优异的苂光效率, 引起了科研工作者的强烈兴趣. 对于菲并咪唑基团 深蓝光材料的分子设计及其光物理性能研究具有重要的意义. 综述了近几年来含有菲并咪唑类基团蓝光材料的发展状 况，对菲并咪坐基团衍生物电致发光器件的发光机理、设计思路与最新进展进行了综述，并对其在未来全彩显示和固 态照明领域上的前景进行了展望.
\end{abstract}

关键词＼cjkstart菲并咪唑; 蓝光材料; 有机电致发光; 有机发光二极管

\section{Progress on Phenanthroimidazole Derivatives in Blue-Emitting Materials}

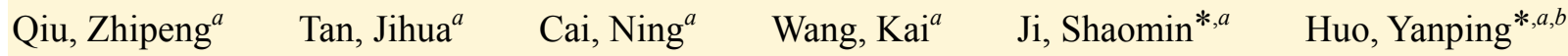 \\ ( ${ }^{a}$ School of Chemical Engineering and Light Industry, Guangdong University of Technology, Guangzhou 510006) \\ $\left({ }^{b}\right.$ Key Laboratory of Organofluorine Chemistry, Shanghai Institute of Organic Cheimstry, \\ Chinese Academy of Sciences, Shanghai 200032)
}

\begin{abstract}
The impending global energy crisis and inefficient energy utilization have driven the use of energy efficient devices for display and lighting applications. Energy-efficient organic light emitting diodes (OLEDs) are considered to be the next generation of smart displays, becoming one of the most competitive candidate for future energy-efficient lighting sources. The molecular design of high-efficiency deep blue materials are greatly limited due to their inherent wide bandgap, poor carrier charge balance and their low efficiency in the solid state. As a novel building block for blue-emitting materials, phenanthroimidazole (PI) group is attractive stems from their bipolar feature and excellent fluorescence efficiency, which has aroused strong interest of researchers. Molecular design and photophysical properties of phenanthroimidazole-based deep blue-emitting materials are of great significance. In this review, an overview of the recent studies on PI-based blue emitters for applications in organic light-emitting diodes (OLEDs) is presented. The luminescence mechanism, design and latest developments of the electroluminescent devices fabricated from phenanthroimidazole derivatives are described, and their prospects in the future of full-color display and solid-state lighting are forecasted.

Keywords phenanthroimidazole; blue emitter; organic electroluminesence; organic light-emitting diodes
\end{abstract}

有机电致发光二极管(Organic Light-Emitting Diodes, OLEDs)由于其轻薄的厚度与重量、鲜艳的色彩、 低功耗、迅速的响应速度及可柔性显示等特点, 在平板
显示和固体照明领域有着广阔的发展和应用前景 ${ }^{[1,2]}$. OLED 属于载流子双注入型发光器件, 发光机理为: 在 外界电场的驱动下，电子和空穴分别由阴极和阳极注入

\footnotetext{
* Corresponding authors. E-mail: smji@gdut.edu.cn; organicteacherhuo@126.com

Received July 3, 2018; revised September 20, 2018; published online October 19, 2018.

Project supported by the Natural Science Foundation of Guangdong Province (No. 2017A030310039), the National Natural Science Foundation of China (No. 61671162), the Science and Technology Planning Project of Guangdong Province (No. 2016A010103031), the Key Project of Educational Commission of Guangdong Province (No. 2017KZDXM025), the Science and Technology Planning Project of Guangdong Province (No. 201707010243), and the Guangdong Youth Pearl River Scholar (2016).

广东省自然科学基金(No. 2017A030310039)、国家自然科学基金(No. 61671162)、广东省科技计划(No. 2016A010103031)、广东省教育厅应用研究重 大项目(No. 2017KZDXM025)、广州市科技计划项目(No. 201707010243)、广东省青年珠江学者(2016)资助项目.
} 
到有机电子传输层和空穴传输层, 并在有机发光层中复 合生成激子, 激子辐射跃迁回到基态并发光 ${ }^{[3]}$. 众所周 知, 全彩显示或固态发光均需要红色、绿色和蓝色(red, green and blue, RGB)三种基本色光, 目前红光与绿光材 料的发展良好, 由于红光及绿光磷光材料的出现, 更是 大大加快了红、绿光器件的应用, 使其寿命、效率及价 格都足以匹配商业化的应用. 根据国际照明委员会 (Commission Internationale del'Eclairage, CIE) 发布的坐 标标准: 美国电视委员会(US National Television Systems Committee, NTSC) 对标准蓝光材料的 CIE 坐标值 定义为 $x+\mathrm{y}<0.30$, 深蓝光材料的 CIE 坐标 $y<0.08^{[5]}$; 欧洲广播联盟(European Broadcasting Union, EBU)规定 深蓝光材料的 CIE 坐标 $y<0.06^{[8,9]}$. 作为 OLED 技术核 心的发光材料, 由于蓝光有机半导体材料禁带较宽 ${ }^{[4]}\left(E_{\mathrm{g}}\right.$ $>3.0 \mathrm{eV}$ ), 其电子能级与器件电极能级匹配性较差, 影 响了载流子的有效注入 ${ }^{[1,5 ~ 7]}$, 所以高效率且色彩饱和 的蓝光材料目前的发展仍然不尽人意. 而且由于其自身 的宽禁带, 可以通过能量转移转化为其他光色 ${ }^{[10,11]}$. 因 此, 提高蓝光材料的发光性能成为当下 OLED 发展的首 要任务, 旨在减少能量损耗及拓展全彩 OLED 的色 域 ${ }^{[12 \sim 14]}$.

目前报道的蓝光材料主要是基于葱 ${ }^{[7,15,16]}$ 、萠 ${ }^{[17]}$ 、 芴 ${ }^{[18]}$ 、芳胺 ${ }^{[19]}$ 、咔唑 ${ }^{[20]}$ 、砜 ${ }^{[21,22]}$ 等为构筑基元的衍生物. 近几年来, 菲并咪唑(Phenanthroimidazole, PI)由于其较 高的溶液、薄膜光致发光效率, 高荧光量子产率, 相对 平衡的载流子注入和传输能力 ${ }^{[23,24]}$, 优秀的热力学稳定

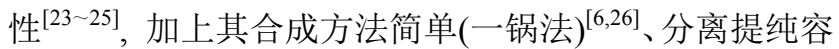
易、结构调控方便等特点, 在高效蓝光材料的研究与应 用上极具潜力, 成为广大科研工作者关注的焦点 ${ }^{[27-29]}$.

\section{1 菲并咪唑的结构特征及其衍生物的合成}

菲并咪唑是一种含氮杂环共轭基团(五元氮杂环及 菲共轭单元组成), 整个 PI 结构呈现出刚性平面共轭结 构, 有利于分子内电子分布的离域化, 电荷偶极矩增大, 菲环较大的平面共轭面积, 加大分子的光吸收截面, 可 以有效地减少了非辐射跃迁的能量损失并提供高的荧 光量子产率，同时促进分子的热稳定性.

另外, 咪唑环上 N1 和 N3 两个截然不同的氮原子, 一号位氮原子类似吡咯为富电子态; 三号位氮原子和嘧 啶上的氮原子相似, 为缺电子态 ${ }^{[30]}$, 这样的结构使得菲 并咪唑基团本身就具有双极性(图 1), 使其具有平衡的 载流子运输能力 ${ }^{[25,27]}$, 有益于降低驱动电压及加大发光 层的激子形成区，从而改善设备在强电场下的效率滚降 问题; 再加上咪唑环的非中心对称结构具有闭合的 $\pi$ 键, 更易于给电子基团和吸电子基团的修饰，修饰后给分子
提供合适的空穴传输能力和电子传输能力. 除此之外, 菲并咪唑基团本身较宽的禁带 ${ }^{[31]}$ 可以通过能量转移完 成长波长的发射, 便于构造全彩显示的发光器件. 菲并 咪挫基团可以应用于电子传输层、载流子阻挡层、发光 层等有机电致发光领域.

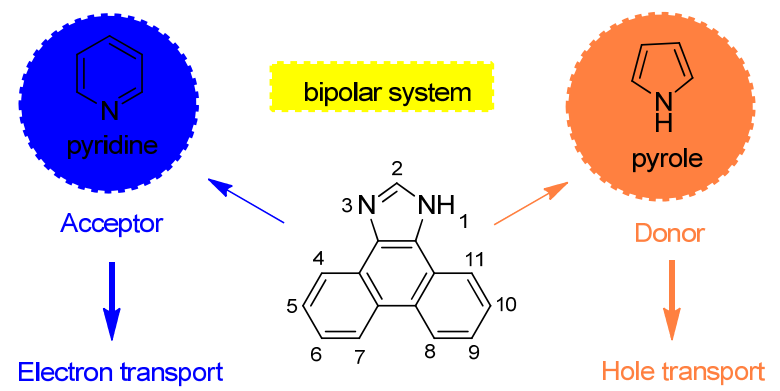

图 1 菲并咪唑的双极性结构

Figure 1 Bipolar properties of PI blocking

在下节中, 我们将展示合成 PI 衍生物的方法, 及其 光物理性质、热稳定性和电致发光性质。

当 $\mathrm{N} 1$ 和 $\mathrm{C} 2$ 位置上分别修饰一个苯环时, 得到最普 遍的衍生物 1,2-二苯基菲并咪唑(PPI，图 2) ${ }^{[32]}$, 这是菲 并咪唑一个十分典型的衍生物, 在波长 $375 \mathrm{~nm}$ 的苂光 灯照射下为深蓝光, 是一种典型深蓝宽禁带材料. 因为 N1 位置上的苯环与菲并咪唑平面存在很大的扭曲角 $\left(85^{\circ}\right)$, 基本接近垂直, 这样可以抑制分子内聚集，阻挡 分子内电荷转移 (intramolecular charge transfer, ICT), 从 而保证其深蓝色发射. 另外 C2 位置上的苯环与菲并咪 唑平面接近平行 $\left(30^{\circ}\right)$, 有利于与 PI 平面形成电子云的 有效跃迁.

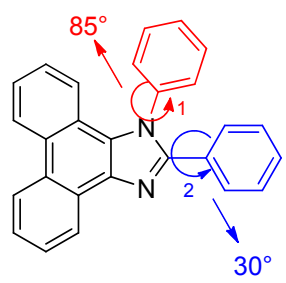

图 2 PPI 的结构

Figure 2 Structure of PPI

由于 $\mathrm{C} 2$ 及 $\mathrm{N} 1$ 这 2 个位点分别进行取代基修饰时, 对材料性能存在显著差异性影响, 因为 $\mathrm{C} 2$ 取代基参与 分子前线轨道的形成, 并且 N1 取代不会导致显著的光 物理变化, 主要是由于取代基和 PI 骨架之间的垂直构 型. 所以在提升整个分子的共轭长度上比 $\mathrm{N} 1$ 取代基更 有效果, 所以在 PI 衍生物的分子构想上, C2 位上的修 饰便格外重要, 决定着其衍生物分子的发光颜色. 研 究表明当 $\mathrm{N} 1$ 被给电子基团或弱吸电子基团组取代时, 
材料的色纯度可以提高; 当被强吸电子基团取代时， 材料发射会红移导致其色纯度降低，且 N1 位置的取代 基可以调控分子的溶解性 ${ }^{[33]}$. 由于 $\mathrm{N} 1$ 和 $\mathrm{C} 2$ 位置的基 团可以通过 “一锅法” 实现修饰(Scheme 1), 所以如何 选择合适的基团取代从而实现菲并咪唑衍生物的高效 蓝光发射, 成为当前研究的一个热点.
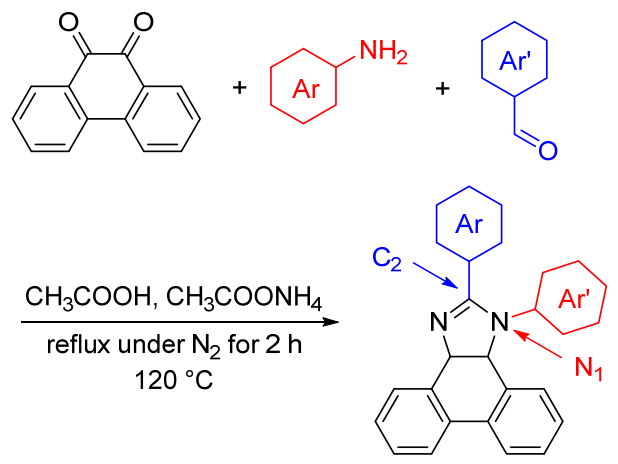

图式 1 一锅法合成菲并咪唑衍生物

Scheme 1 One-pot reaction for synthesis of PI derivatives

此外在菲并咪唑 $\mathrm{C} 6$ 及 $\mathrm{C} 9$ 位置上引入合适的取代 基(Scheme 2), 同样可以利用控制共轭长度达到调控其 发射光色的作用, 并且增强其热稳定性. 通过理论计算 表明, 菲并咪唑 $\mathrm{C} 6$ 及 $\mathrm{C} 9$ 位置上的取代基其电负性并不 相同, 这种不对称性归因于咪唑环中的两个不同的氮原 子. 另一方面, C6 和 C9 处的芳基取代会加深其衍生物 的最低未占据轨道(Lowest Unoccupied Molecular, LU$\mathrm{MO}$ )能级, 更有利于电子注入过程. 一般来说, 衍生物 的最高占据轨道(Highest Occupied Molecular, HOMO)主 要分布在菲并咪唑部分, 而 LUMO 分布倾向于集中在 C9 连接芳族基团上, 而 C6 取代基的贡献要小得多. 这 种不对称性很可能源于菲并咪唑中 C6 和 C9 原子的对 LUMO 贡献的不同. 根据共振理论, 共轭孤对电子可以 转移到 $\mathrm{C} 6$ 或 $\mathrm{C}$. 电子向 $\mathrm{C} 6$ 的迁移更有利, 因为它导致 最大的电荷分离距离, 这种优选的电子结构导致 C6 位 置的电荷累积. 因此, 菲并咪唑这种独特的电子结构诱 导 HOMO 和 LUMO 倾向于分别在 C6 和 C9 取代基处 分布. 并且实验结果也表明 $\mathrm{C} 6$ 及 $\mathrm{C} 9$ 位置上的取代基存 在很强的 ICT 现象, 且衍生物的光物理性质受取代基的 大小和共轭程度以及连接空间位阻的影响很大. 同传统 $\mathrm{C} 2$ 位修饰相比, C6 及 $\mathrm{C} 9$ 位置修饰能提供更适宜的共轭 长度. 此外, 这两个位置取代菲并咪唑衍生物的 ICT 特 性随着取代芳族基团的大小而增加, 并且受空间位阻的 影响, 其中葱和萠衍生物具有最强的 ICT 激发性质. 所 以, 如何选取适当基团从而构建高效蓝光的 $\mathrm{C} 6$ 及 $\mathrm{C} 9$ 位 置取代菲并咪唑衍生物, 也颇受关注.

下文将详细介绍常见的电子给体 $-\pi$ - 电子受体 (Doner- $\pi$-Accepter, D- $\pi$-A)型及非 D- $\pi$-A 型菲并咪唑蓝
光材料及其在 OLED 器件的应用. 所述蓝光材料及其 OLED 器件光电性质数据列于表 1 .

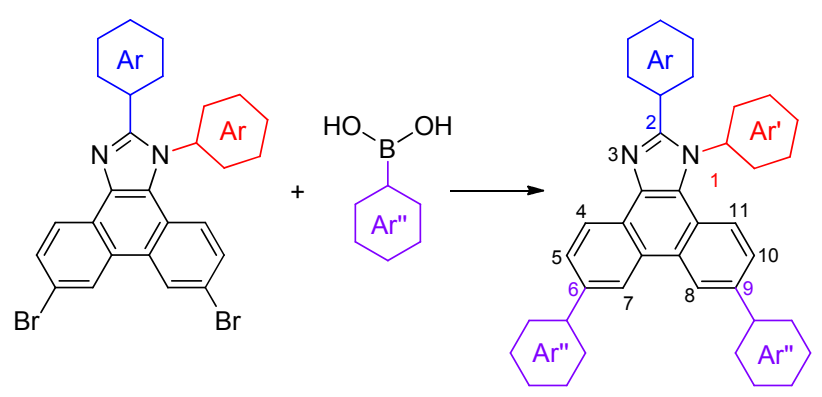

图式 2 Suzuki 反应合成菲并咪唑衍生物

Scheme 2 Suzuki reaction for synthesis of PI derivatives

\section{2 具有 D-T-A 结构的菲并咪唑衍生物}

为了在阳极/有机/阴极系统中获得高的电致发光效 率，最理想的情况便是有机层同时具备有空穴-电荷注 入能力和双极传输能力 ${ }^{[34]}$. 这不仅要求发光层需要具 有与阳极和阴极的工作功能相匹配的 HOMO 和 LUMO 能级, 而且还要求发光层能够承受在两个电极之间传输 电荷的氧化还原作用 ${ }^{[35]}$. 目前有效地获得优秀电荷转 移能力的策略是将给体与受体结合在同一个分子中, 形 成 $\mathrm{D}-\mathrm{A}$ 型或者 $\mathrm{D}-\pi-\mathrm{A}$ 型结构 ${ }^{[36]}$ ，这样做的好处是因为给 体基团可以提供良好空穴传输能力, 并且降低其最高占 据轨道的能级使得空穴注入过程更加容易; 与此同时, 受体基团的引入使得分子具备一定的电荷传输能力, 并 能降低其最低未占据轨道的能级, 有利于电子注入过 程 ${ }^{37 \sim 39]}$.

双极有机分子的一个很有潜力的策略是同时将给 电子基团和吸电子基团结合到分子中. 如前所述, PI 展 示了双极电子特性，从它的 $\mathrm{N}$ 原子的两种不同的共轭模 式中分离出来. 因此, 当一个中性基团或吸电子基团键 连在它的 $\mathrm{C} 2$ 位置时, PI 可以作为一个给电子基团. 它与 一个给电子基团相键联, 表现出吸电子的性质 ${ }^{[27]}$. 所 以，菲并咪唑基团是构造双极性 D- $\pi-\mathrm{A}$ 分子的一个典型 单元, 这种独特的性质也使得 D- $\pi$-A 型菲并咪唑衍生物 的研究成为热点.

\section{1 局域杂化电荷转移激发态的 D-ா-A 型菲并咪唑衍 生物}

一般来说, 苂光材料都是依赖 $\pi-\pi$ 跃迁而激发, 并 且它们通过其局域激发态(locally excited states，LE 态) 实现高的荧光量子产率 $\left(\varphi_{\mathrm{PL}}\right)$. 但是在 OLED 器件中, 由 于高激子结合能 $(>1 \mathrm{eV})$ 的电子-空穴对，导致基于 LE 态的电致发光材料存在自旋反转现象, 结果使电子转化 为光子的效率大大降低 ${ }^{[40]}$. 另一方面, 典型 D-A 分子的 另外一种激发态-电荷转移态(charge transfer states, CT 
表 1 分子在溶液中或分散在主体薄膜或非掺杂成膜中光致发光波长 $\left(\lambda_{\mathrm{PL}}\right)$ 、苂光量子产率(PLQY)、通过溶液状态的起始吸收波长 测量 $\left(E_{\mathrm{g}}\right)$ 、用二茂铁作为参考, HOMO 能级由氧化电位确定, $\mathrm{LUMO}$ 由 $E_{\mathrm{g}}$ 和 HOMO 能级确定 $(\mathrm{CV})$ 、启动电压 $\left(V_{\mathrm{on}}\right)$ 、电流效率 $(\mathrm{CE})$ 、 电源效率 $(\mathrm{PE})$ 、电致发光波长 $\left(\lambda_{\mathrm{EL}}\right)$ 和最大半峰宽 $(\mathrm{FWHM})$ 、最大外量子效率 $(\mathrm{EQE})$ 以及 $\mathrm{CIE}$ 色坐标

Table 1 PL peak $\left(\lambda_{\mathrm{PL}}\right)$ in solution or in neat film, photoluminescence quantum yield (PLQY), measured by the onset absorption wavelength of solution state $\left(E_{\mathrm{g}}\right)$, HOMO determined from the onset of oxidation potentials with ferrocene as reference; LUMO determined from $E_{\mathrm{g}}$ and HOMO level $(\mathrm{CV})$; onset voltage $\left(V_{\mathrm{on}}\right)$, current efficience, power efficiency, EL peak $\left(\lambda_{\mathrm{EL}}\right)$ and full width at half maxima (FWHM), maximum EQE, CIE for based blue emitters and OLEDs

\begin{tabular}{|c|c|c|c|c|c|c|c|c|c|c|c|}
\hline Compd. & $\lambda_{\mathrm{PL}} / \mathrm{nm}$ & PLQY/\% & $E_{\mathrm{g}}$ & $\mathrm{CV}$ & $V_{\text {on }} / \mathrm{V}$ & $\mathrm{CE} /\left(\mathrm{cd} \cdot \mathrm{A}^{-1}\right)$ & $\mathrm{PE} /\left(\mathrm{lm} \cdot \mathrm{W}^{-1}\right)$ & $\lambda_{\mathrm{EL}}(\mathrm{FWHM}) / \mathrm{nm}$ & $\mathrm{EQE} / \%$ & CIE & Ref. \\
\hline 1 & $438 / 440$ & $90 / 90$ & 3.0 & $-5.22 /-2.27$ & - & 5.66 & 6.13 & $434(60)$ & 5.02 & $(0.15,0.11)$ & $\overline{[24]}$ \\
\hline 2 & $480 / 460$ & $7.8 / 13$ & - & - & - & - & - & - & 2.20 & - & [42] \\
\hline 3 & $451 / 445$ & $79 / 40$ & - & - & - & 10.5 & 5.5 & - & 7.80 & $(0.16,0.16)$ & {$[43]$} \\
\hline 4 & $442 / 436$ & - & 2.9 & $-5.26 /-2.36$ & 2.80 & 2.63 & 2.53 & $448(71)$ & 3.08 & $(0.15,0.09)$ & {$[23]$} \\
\hline 5 & $424 / 448$ & $82 / 63$ & 3.1 & $-5.26 /-2.16$ & 2.52 & 3.60 & 3.66 & $448(70)$ & 4.56 & $(0.15,0.08)$ & [44] \\
\hline 6 & $483 / 469$ & $94 / 72$ & 2.9 & $-5.25 /-2.35$ & 2.15 & 10.9 & 10.5 & $471(80)$ & 5.64 & $(0.17,0.29)$ & [44] \\
\hline 7 & $428 / 414$ & $85.2 / 64.2$ & 3.0 & $-5.33 /-2.29$ & 3.00 & 1.70 & 1.44 & $435(60)$ & 3.38 & $(0.154,0.063)$ & {$[45]$} \\
\hline 8 & $428 / 450$ & $\sim 100 / 90.5$ & 3.2 & $-5.50 /-2.44$ & 3.10 & 5.00 & 5.15 & $448(61)$ & 5.95 & $(0.157,0.084)$ & [45] \\
\hline 9 & $425 / 433$ & $\sim 100 / 96.8$ & 3.1 & $-5.54 /-2.40$ & 3.20 & 3.29 & 2.80 & $436(62)$ & 5.09 & $(0.157,0.074)$ & {$[45]$} \\
\hline 10 & $448 / 440$ & $81.7 / 66.8$ & 3.0 & $-5.27 /-2.27$ & 3.00 & 4.40 & 4.60 & $440(59)$ & 7.20 & $(0.150,0.063)$ & [46] \\
\hline 11 & $443 / 449$ & $81.2 / 68.0$ & 3.0 & $-5.32 /-2.30$ & 3.00 & 3.98 & 3.88 & $448(61)$ & 6.33 & $(0.151,0.066)$ & {$[46]$} \\
\hline 12 & $435 / 444$ & $94.2 / 79.5$ & 3.2 & $-5.48 /-2.30$ & 3.00 & 3.03 & 2.98 & $440(93)$ & 4.30 & $(0.15,0.08)$ & [47] \\
\hline 13 & $420 / 438$ & $87.3 / 74.2$ & 3.2 & $-5.57 /-2.35$ & 3.20 & 2.82 & 2.72 & $436(88)$ & 4.50 & $(0.15,0.07)$ & [47] \\
\hline 14 & $415 / 427$ & $-/ 52$ & 3.0 & $-5.56 /-2.50$ & 3.20 & 1.57 & 1.34 & $444(65)$ & 2.37 & $(0.153,0.074)$ & [48] \\
\hline 15 & $428 / 444$ & $-/ 69$ & 3.0 & $-5.52 /-2.54$ & 3.30 & 3.73 & 2.72 & $448(65)$ & 5.20 & $(0.152,0.080)$ & {$[48]$} \\
\hline 16 & $432 / 428$ & $-/ 95$ & 3.0 & $-5.52 /-2.52$ & 3.20 & 4.23 & 3.40 & 448 (64) & 5.75 & $(0.153,0.082)$ & [48] \\
\hline 17 & $450 / 448$ & $14 / 9$ & 3.3 & $-5.86 /-2.61$ & - & - & - & - & - & - & [39] \\
\hline 18 & $429 / 443$ & $72 / 20$ & 3.3 & $-5.72 /-2.52$ & 3.40 & 3.82 & 2.86 & 440() & 5.80 & $(0.150,0.080)$ & [39] \\
\hline 19 & $443 / 457$ & $86 / 88$ & 3.1 & $-5.47 /-2.36$ & 2.80 & 6.37 & 6.37 & $444(62)$ & 6.67 & $(0.152,0.095)$ & [49] \\
\hline 20 & $420 / 442$ & $93 / 85$ & 3.0 & $-5.54 /-2.51$ & 2.90 & 2.71 & 2.73 & $436(65)$ & 5.08 & $(0.156,0.061)$ & [49] \\
\hline 21 & $420 / 434$ & $91 / 80$ & 2.9 & $-5.31 /-2.46$ & 2.90 & 2.94 & 2.64 & $440(63)$ & 4.47 & $(0.157,0.071)$ & [49] \\
\hline 22 & $426 / 474$ & $93 / 50$ & 3.2 & $-5.50 /-2.28$ & 2.90 & 3.96 & 2.59 & $440(70)$ & 4.95 & $(0.150,0.092)$ & {$[50]$} \\
\hline 23 & $416 / 436$ & $77 / 43$ & 3.2 & $-5.57 /-2.34$ & 3.30 & 2.46 & 1.20 & $460(62)$ & 4.21 & $(0.152,0.057)$ & {$[50]$} \\
\hline 24 & $417 / 433$ & $82 / 47$ & 3.2 & $-5.58 /-2.43$ & 3.10 & 2.70 & - & $436(60)$ & 4.60 & $(0.154,0.058)$ & {$[50]$} \\
\hline 25 & $411 / 425$ & $77 / 82$ & 3.4 & $-5.62 /-2.21$ & 3.80 & 0.51 & - & $412(65)$ & 2.43 & $(0.160,0.035)$ & [57] \\
\hline 26 & $445 / 446$ & $90 / 57$ & 3.0 & $-5.52 /-2.52$ & 3.20 & 5.88 & - & 448 (78) & 5.11 & $(0.154,0.141)$ & {$[57]$} \\
\hline 27 & $456 / 461$ & $41 / 34$ & 3.0 & $-5.62 /-2.64$ & 3.50 & 3.43 & - & $460(83)$ & 2.29 & $(0.164,0.185)$ & [57] \\
\hline 28 & $442 / 464$ & $62 / 50$ & 2.8 & $-5.55 /-2.78$ & 3.00 & 13.16 & - & $470(80)$ & 9.44 & $(0.14,0.19)$ & {$[60]$} \\
\hline 29 & $-/ 532$ & $-/ 73$ & 2.9 & $-4.73 /-2.21$ & 2.90 & 65.90 & 68.98 & $528(100)$ & 20.5 & - & {$[66]$} \\
\hline 30 & $-/ 531$ & $-/ 99$ & 2.8 & $-4.73 /-2.22$ & 2.90 & 67.18 & 68.11 & $528(98)$ & 21.1 & - & [66] \\
\hline 31 & $458 / 477$ & $60 / 30$ & & $-5.3 /-2.4$ & 4.30 & - & - & $521(150)$ & - & $(0.38,0.49)$ & {$[70]$} \\
\hline 32 & $445 / 459$ & $65 / 31$ & 3.5 & - & 6.50 & 0.29 & - & $491(100)$ & - & $(0.193,0.362)$ & [72] \\
\hline 33 & $445 / 462$ & $64 / 30$ & 3.5 & - & 8.50 & 0.19 & - & $503(80)$ & - & $(0.211,0.386)$ & [72] \\
\hline 34 & $453 / 463$ & $64 / 36$ & 3.5 & - & 5.80 & 0.38 & - & $480(91)$ & - & $(0.191,0.309)$ & {$[72]$} \\
\hline 35 & $450 / 458$ & $65 / 35$ & 3.5 & - & 8.70 & 0.2 & - & $484(93)$ & - & $(0.181,0.270)$ & [72] \\
\hline 36 & - & - & - & - & 7.00 & 0.03 & - & $485(85)$ & - & $(0.183,0.258)$ & [73] \\
\hline 37 & - & - & - & - & - & - & - & - & - & - & [73] \\
\hline 38 & - & - & - & - & 6.20 & 0.05 & - & $459(88)$ & - & $(0.166,0.173)$ & [73] \\
\hline 39 & - & - & - & - & - & - & - & - & - & - & [73] \\
\hline 40 & - & - & - & - & 4.00 & - & - & $480(98)$ & 4.00 & $(0.199,0.332)$ & [79] \\
\hline 41 & - & - & - & - & 4.50 & - & - & $483(98)$ & 2.20 & $(0.212,0.372)$ & [79] \\
\hline 42 & - & - & - & - & 4.00 & - & - & $482(98)$ & 3.40 & $(0.215,0.313)$ & [79] \\
\hline 43 & $413 /-$ & $1.6 /-$ & 2.6 & $-5.12 /-3.48$ & 4.00 & - & - & $490(104)$ & 2.80 & $(0.21,0.36)$ & [80] \\
\hline 44 & $413 /-$ & $0.5 /-$ & 2.8 & $-5.36 /-3.54$ & 4.00 & - & - & $476(98)$ & 4.00 & $(0.19,0.28)$ & [80] \\
\hline 45 & $466 / 458$ & $87.9 / 95.3$ & 3.1 & $-5.87 /-2.76$ & 2.95 & 4.28 & 3.94 & $460(60)$ & 3.03 & $(0.156,0.166)$ & [83] \\
\hline 46 & $463 / 457$ & $71.1 / 81.1$ & 3.0 & $-5.89 /-2.81$ & 3.10 & 3.56 & 2.35 & $456(59)$ & 2.80 & $(0.154,0.154)$ & [83] \\
\hline 47 & $452 / 457$ & $96 / 83$ & 3.1 & $-5.50 /-2.40$ & 3.00 & 6.22 & 5.89 & $460(55)$ & 4.72 & $(0.15,0.16)$ & [91] \\
\hline 48 & $427 / 438$ & $90 / 79$ & 3.0 & $-5.52 /-2.40$ & 2.80 & 4.14 & 4.35 & $440(56)$ & 5.15 & $(0.15,0.09)$ & [91] \\
\hline
\end{tabular}




\begin{tabular}{cccccccccccc}
\multicolumn{10}{c}{ 续表 } \\
\hline Compd. & $\lambda_{\mathrm{PL}} / \mathrm{nm}$ & $\mathrm{PLQY} / \%$ & $E_{\mathrm{g}}$ & $\mathrm{CV}$ & $V_{\mathrm{on}} / \mathrm{V} \mathrm{CE} /\left(\mathrm{cd} \bullet \mathrm{A}^{-1}\right)$ & $\mathrm{PE} /\left(\mathrm{lm} \cdot \mathrm{W}^{-1}\right)$ & $\lambda_{\mathrm{EL}}(\mathrm{FWHM}) / \mathrm{nm}$ & $\mathrm{EQE} / \%$ & $\mathrm{CIE}$ & $\mathrm{Ref}$. \\
\hline $\mathbf{4 9}$ & $436 /-$ & $95 / 84$ & 3.1 & $-5.9 /-2.8$ & 2.9 & 4.76 & 4.68 & $436(60)$ & 5.70 & $(0.15,0.10)$ & {$[92]$} \\
$\mathbf{5 0}$ & $436 /-$ & $89 / 73$ & 3.1 & $-5.8 /-2.7$ & 2.9 & 3.40 & 3.06 & $448(68)$ & 4.20 & $(0.15,0.09)$ & {$[92]$} \\
$\mathbf{5 1}$ & $418 / 433$ & $63 / 49.6$ & 3.2 & $-5.30 /-2.10$ & 2.7 & 1.28 & 1.12 & $414(68)$ & 2.74 & $(0.15,0.05)$ & {$[93]$} \\
$\mathbf{5 2}$ & $391 / 396$ & -15 & 3.3 & $-5.62 /-2.35$ & 3.4 & 0.65 & 0.58 & $420(65)$ & 0.96 & $(0.163,0.076)$ & {$[94]$} \\
$\mathbf{5 3}$ & $409 / 420$ & $-/ 43$ & 3.1 & $-5.52 /-2.40$ & 3.2 & 0.50 & 0.45 & $420(50)$ & 1.45 & $(0.162,0.043)$ & {$[94]$} \\
$\mathbf{5 4}$ & $416 / 432$ & $-/ 61$ & 3.0 & $-5.49 /-2.43$ & 2.8 & 2.17 & 2.27 & $428(60)$ & 1.98 & $(0.161,0.063)$ & {$[94]$} \\
$\mathbf{5 5}$ & $405 / 412$ & $-/ 31$ & 3.1 & $-5.55 /-2.39$ & 3.8 & 0.10 & 0.55 & $420(100)$ & 0.83 & $(0.184,0.116)$ & {$[94]$} \\
$\mathbf{5 6}$ & $405 / 412$ & $-/ 72$ & 3.2 & $-5.54 /-2.38$ & 3.1 & 1.62 & 1.57 & $428(74)$ & 3.72 & $(0.158,0.050)$ & {$[94]$} \\
$\mathbf{5 7}$ & $429 / 456$ & $-/ 69$ & 3.0 & $-5.53 /-2.56$ & 2.6 & 5.92 & 4.97 & $448(90)$ & 3.39 & $(0.200,0.221)$ & {$[94]$} \\
$\mathbf{5 8}$ & $437 / 468$ & $-/ 93$ & 3.0 & $-5.50 /-2.54$ & 2.5 & 8.18 & 8.46 & $460(85)$ & 5.69 & $(0.157,0.177)$ & {$[94]$} \\
$\mathbf{5 9}$ & $421 / 468$ & $93 / 85$ & 3.6 & $-5.47 /-2.29$ & 3.5 & 6.87 & 6.20 & $468(75)$ & 3.4 & $(0.16,0.21)$ & {$[32]$} \\
$\mathbf{6 0}$ & $417 / 451$ & $72 / 60$ & 3.0 & $-5.37 /-2.30$ & 4.2 & 1.52 & 0.66 & $452(86)$ & 0.6 & $(0.30,0.39)$ & {$[32]$} \\
$\mathbf{6 1}$ & $411 / 434$ & $92 / 57$ & 3.1 & $-5.48 /-2.33$ & 4.5 & 0.68 & - & $440(97)$ & - & $(0.16,0.10)$ & {$[96]$} \\
$\mathbf{6 2}$ & $368 / 402$ & $55 / 35$ & 3.3 & $-5.48 /-2.18$ & 4.5 & 0.45 & - & $440(94)$ & - & $(0.16,0.11)$ & {$[96]$} \\
$\mathbf{6 3}$ & $389 / 397$ & $68 / 27$ & 3.4 & $-5.51 /-2.12$ & 3.5 & 0.95 & 0.93 & $440(82)$ & 2.36 & $(0.156,0.050)$ & {$[97]$} \\
$\mathbf{6 4}$ & $393 / 429$ & $40 / 13$ & 3.2 & $-5.63 /-2.48$ & 4.0 & 0,89 & 0.66 & $447(80)$ & 1.17 & $(0.150,0.080)$ & {$[97]$} \\
\hline
\end{tabular}

态), 能够通过电荷注入实现自旋反转, 并通过减少单三线态的能级差, 从而促进荧光器件中单线态激子的利 用率，显著增加激子利用率 $\left(\eta_{\mathrm{r}}\right)$. 然而，具有过强的 D-A 型结构 $\mathrm{CT}$ 态分子常常表现着伴随最大发射半波长变宽 的发射红移, 导致器件色纯度的下降. 与此同时, 分子 前线轨道的重叠缺乏会导致荧光量子产率的降低. 由外 量子产率(External Quantum Efficiency, EQE)公式 ${ }^{[41]}$

$$
\mathrm{EQE}=\gamma \eta_{\mathrm{out}} \varphi_{\mathrm{PL}} \eta_{\mathrm{r}}
$$

荧光量子产率 $\left(\varphi_{\mathrm{PL}}\right)$ 和激子利用率 $\left(\eta_{\mathrm{r}}\right)$ 是决定 $\mathrm{EQE}$ 的重要 因素, 由上可知单一的 LE态或 CT 态分子并不能同时具 备高的荧光量子产率 $\left(\varphi_{\mathrm{PL}}\right)$ 和激子利用率 $\left(\eta_{\mathrm{r}}\right)$, 在 OLED 器件中, 注入的空穴和电子经过复合形成电子对或 $\mathrm{CT}$ 激子, 该激子经过衰变产生一个光子或转换至一个低能 级的 LE 激子, 而局域激发态 LE 态可以实现高的苂光量 子产率.

为了充分利用 $\mathrm{LE}$ 态和 $\mathrm{CT}$ 态的优势, $\mathrm{Ma}$ 等 ${ }^{[24]}$ 报道 了一系列具有高效率的 D- $\pi-\mathrm{A}$ 型分子, 并阐明合适的 $\mathrm{D}-\pi-\mathrm{A}$ 结构可以形成一个新的局域杂化电荷转移激发态 (hybrid local and charge transfer excited state, HLCT 态), 可以同时实现高的苂光量子产率和激子利用率. 分子内 给受体间电荷转移跃迁的 CT 态和局域激发态 LE 态完 美结合的分子, 在实现高激子利用率的同时也达到了高 的苂光量子产率, 所以 $\mathrm{CT}$ 态和 LE 态的充分利用可以促 进 OLED 器件的效率(图 3).

早在 2011 年, $\mathrm{Ma}$ 等 ${ }^{[24]}$ 通过基于三苯胺(Triphenylamine, TPA)及 PPI 的基团, 构建了一个分子内给受体间 电荷转移跃迁的 HLCT 态分子 1 (图 4). 经过溶剂化实验 发现在低极性溶液时, 分子都存在明显的精细振动结 构, 为典型的 $\mathrm{LE}$ 态分子; 随着溶剂极性的上升(正己

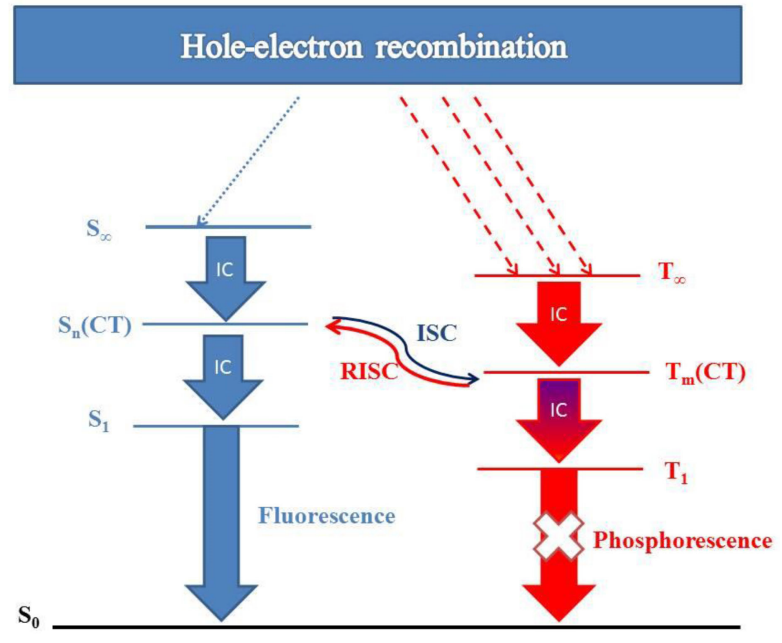

图 3 HLCT 材料机理图

Figure 3 HLCT emiter mechanism diagram

烷一乙腈), 苂光发射图谱皆有明显的红移 $(57,78,55$ $\mathrm{nm})$, 表明它们是典型的 CT 态分子. 经过斯托克斯位移 与溶液极性的关系, 在这个过程中他们发现中等极性时 LE 态和 CT 态存在一定的杂化, 从而形成一个新的激发 态, 这就是局域杂化电荷转移激发态, 这个激发态下存 在一个 “热激子” 的通道, 可以使三线态的激子通过反 系间窝越到达单重态，从而提高其单线态激子利用率. 其溶液及固体都达到了 $90 \%$ 的苂光量子产率, 由它构造 的非掺杂器件 ITO/ $\mathrm{MoO}_{3}(10 \mathrm{~nm}) / \mathrm{NPB}(80 \mathrm{~nm}) / \mathrm{TCTA}(5$ $\mathrm{nm}) / \mathbf{1}(20 \mathrm{~nm}) / \mathrm{TPBi}(40 \mathrm{~nm}) / \mathrm{LiF}(1 \mathrm{~nm}) / \mathrm{Al}(100 \mathrm{~nm})$, 最 大电流效率和外量子效率达到 $5.66 \mathrm{~cd} \cdot \mathrm{A}^{-1}$ 和 $5.02 \%$, $\mathrm{CIE}$ 坐标为 $(0.15,0.11)$. 由其非掺杂器件的外量子效率 计算得到其激子利用率超过荧光发光材料 $25 \%$ 的自选 统计限制(由单三重态激子比例为 $1: 3$ ). 


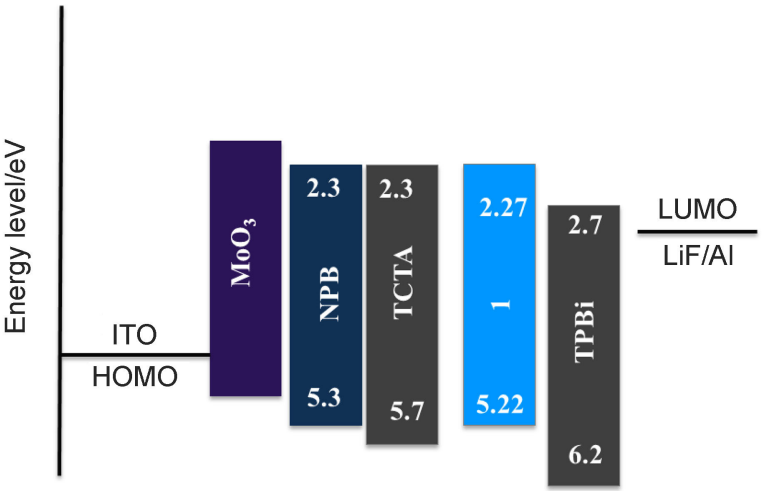

图 41 的电致发光器件及其电子能级图 ${ }^{[24]}$

Figure 4 EL structures and electronic level configurations of the devices 1

2015 年, $\mathrm{Ma}$ 等 ${ }^{[42,43]}$ 通过在 N1 位置引入了强吸电子 能力的氧基及增加 TPA 与 PPI 间的桥联长度, 后续设计 了 $2 、 3$ 两个分子. 2 分子表现出更强的 CT 态特征, 溶剂 化光谱较 1 红移了 $22 \mathrm{~nm}$, 器件最大外量子效率达到 $2.2 \%$, 估算出的激子利用率可高达 $85 \%$. 与 2 相比, 3 在 苂光发射谱图中显示出精细的振动结构及更窄的最大 半波峰, 表明其分子激发态 LE 态占据一定组分, 因此 可以拥有更高的苂光量子产率. 不同于热活化延迟苂光 材料, 3 分子中 CT 态和 LE 态的平衡结合形成 HLCT 的 杂化平衡, 具有更高的激发态, 形成一种新的 “热 $\mathrm{CT}$ ” 通道, 导致可以产生超快速的反向隙间窝越过程, 将三 线态激子 $T_{\mathrm{m}}(\mathrm{CT})$ 传递到单线态 $S_{\mathrm{n}}(\mathrm{CT})$, 再经过内转换
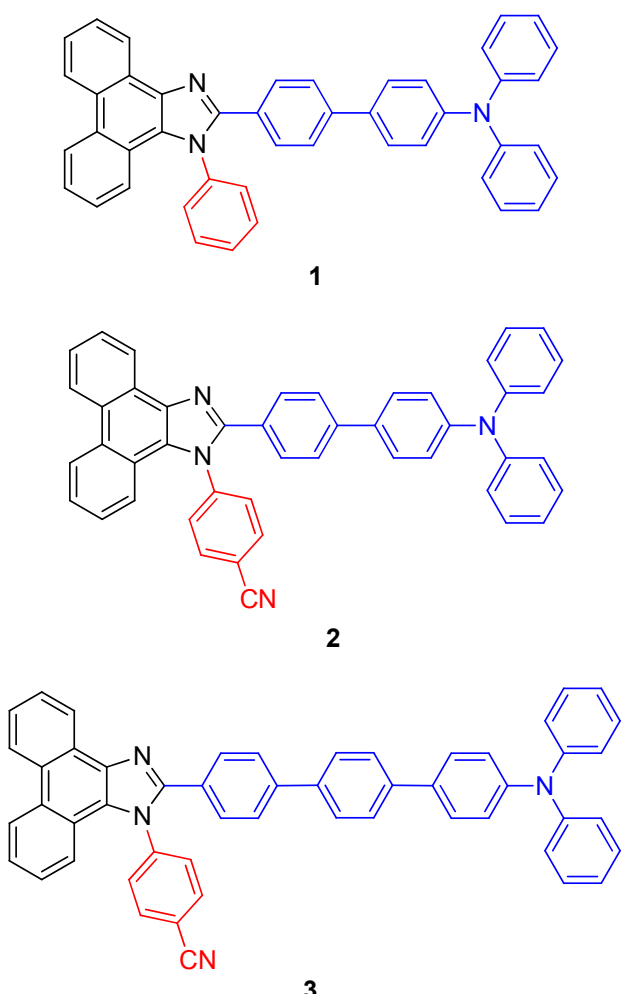

至最低激发单重态 $S_{0}$. 这种现象在其电致发光器件尤 为明显. 非掺杂器件的最大电流密度达到 $10.5 \mathrm{~cd} \cdot \mathrm{A}^{-1}$, 最大外量子效率为 $7.8 \%$ ，以及近乎 $100 \%$ 的激子利用率. 显示具有 HLCT 态的分子其电致发光器件的卓越性能.

将分子 3 菲并咪唑集团 N1 位置上苯环的取代基换 为叔丁基, 得到的分子 $4^{[23]}$ 是一个典型的 D- $\pi-A$ 结构的 分子, 以其为发光层的器件电流效率为 $0.65 \mathrm{~cd} \cdot \mathrm{A}^{-1}$, 电 源效率为 $0.68 \mathrm{~lm} \cdot \mathrm{W}^{-1}$ ，最大外量子效率 $\mathrm{EQE}$ 为 $1.37 \%, \mathrm{CIE}$ 坐标为 $(0.15,0.05) .2016$ 年, Tong 等 ${ }^{[44]}$ 在 4 分子的基础上, 分别在 C6 和 C9 号位引入菲和萠两个不 同的芳香官能团，合成两个具有局域杂化-电荷转移激 发态的分子 5 和 6 . 以两个分子构筑 OLED 器件结构为: ITO/NPB (70 nm)/TCTA $(5 \mathrm{~nm}) / \mathbf{5}$ 或 $6(30 \mathrm{~nm}) / \mathrm{TPBi}(40$ $\mathrm{nm}) / \mathrm{LiF}(1 \mathrm{~nm}) / \mathrm{Al}(150 \mathrm{~nm})$, 其中以 $\mathbf{5}$ 为发光层的非掺 杂器件 CIE 坐标为 $(0.15,0.08)$, 最大外量子产率 $\mathrm{EQE}$ 为 $4.56 \%$, 电流效率为 $3.60 \mathrm{~cd} \bullet \mathrm{A}^{-1}$, 电源效率为 $3.66 \mathrm{~lm} \bullet$ $\mathrm{W}^{-1}$, 除此以外, 以 6 为非掺杂器件的器件是当时性能 最好的天蓝色器件, 启动电压仅为 $2.15 \mathrm{eV}$, 并且外量子
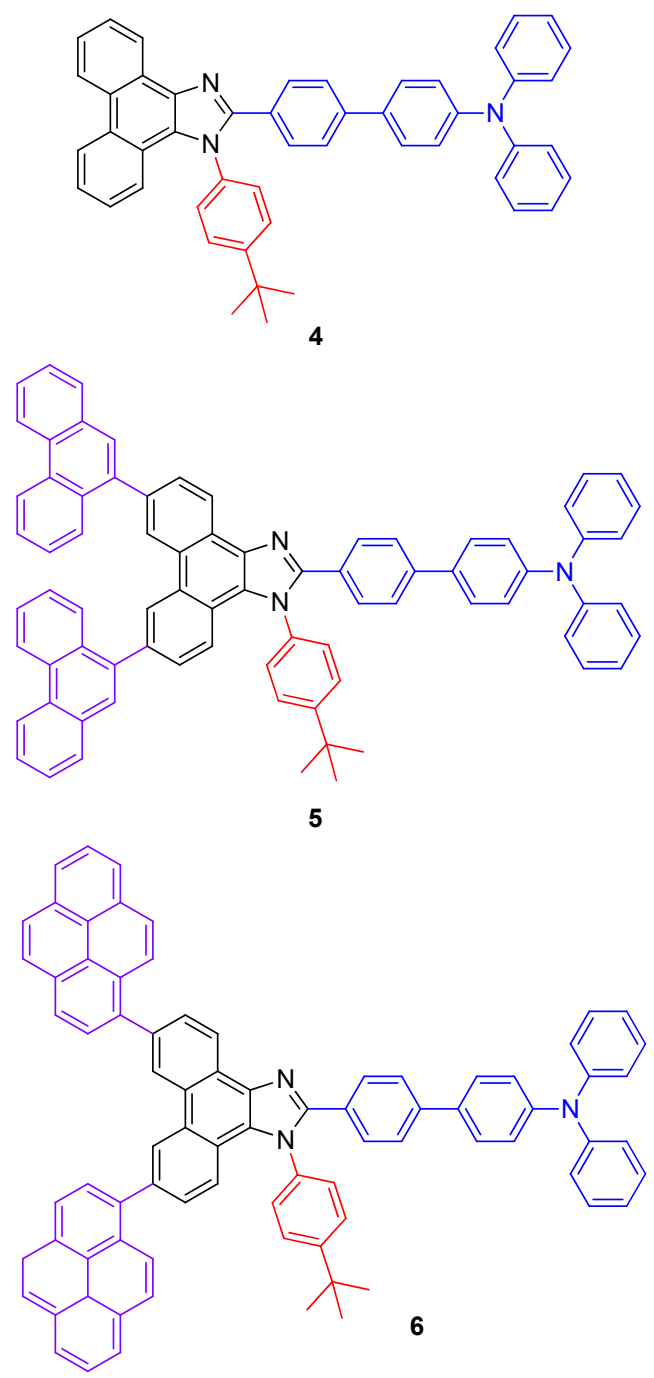
产率达到了 $5.64 \%$. 两个器件都表现出微弱的效率滚降, 由于局域杂化-电荷转移激发态的存在, 其单线态激子 利用率分别达到了 $36.2 \%$ 及 $39.2 \%$. 证明了 C6 和 C9 号 位上的菲和萠可以使得原本为 LE 态的分子 4 转换为 HLCT 态, 大大增强其激子利用率及器件性能.

为了达到 HLCT 态的短波长(440 nm 左右)发射, 供 体和受体的选择需要满足推电子和吸电子能力的适当 平衡, 才能同时拥有 CT 态和 LE 态. 2017 年, Tong 等 ${ }^{[45]}$ 报道了一系列以菲并咪唑和咔唑为基团的 $\mathrm{D}-\pi-\mathrm{A}$ 结构 的苂光材料 7 9, 其以菲并咪唑为弱吸电子集团, 咔唑 为给电子基团, 由于菲并咪唑和咔唑基团都是刚性共轭 结构, 可以实现高的荧光量子产率, 通过使用不同的 $\pi$ 共轭桥连接, 研究其在发射波长的性质. 菜基和联荎基 的引入使 8 和 9 热稳定性提高(热分解温度 $T_{\mathrm{d}}=480$ 和 $\left.510{ }^{\circ} \mathrm{C}\right)$, 此外具有较大电子亲和能的联菱基的加入, 使得 9 的 LUMO 能级比 8 更低 $(-2.40$ 和 $-2.44 \mathrm{eV})$, 同 时其两个菜基二面角增大导致共轭阻断, 更有利于深蓝 发射. 由于菜基和联萗基自身弱的给电子能力, 使得 $\mathbf{8}$ 和 9 不同于 7 的 LE 激发态, 更倾向 CT 态, 使得其溶剂 化红移明显, 并显示出 HLCT 态的性质, 证明 $n$-型 $\pi$ 共 轭桥的引入有利于 HLCT 态的构建. 以三个分子为器件 的 OLED 都集中在蓝紫发射, 并显示出不错的电致发光 性能, ITO/NPB (70 nm 7 或 8, $50 \mathrm{~nm}$ 9)/TCTA (5 nm)/8 或 $9(30 \mathrm{~nm}) / \mathrm{TPBi}(30 \mathrm{~nm}) / \mathrm{LiF}(1 \mathrm{~nm}) / \mathrm{Al}(100 \mathrm{~nm})$, 在 1000 $\mathrm{cd} \cdot \mathrm{m}^{-2}$ 的 $\mathrm{CIE}$ 坐标分别为 $(0.154,0.063),(0.157$,<smiles>CC(C)(C)c1ccc(-n2c(-c3ccc(-c4ccc5c(c4)c4ccccc4n5-c4ccccc4)cc3)nc3c4ccccc4c4ccccc4c32)cc1</smiles><smiles>CC(C)(C)c1ccc(-n2c(-c3ccc(-c4ccc(-c5ccc6c7n(-c8ccccc8)c(c6c5)=CC=CC=7)c5ccccc45)cc3)nc3c4ccccc4c4ccccc4c32)cc1</smiles>

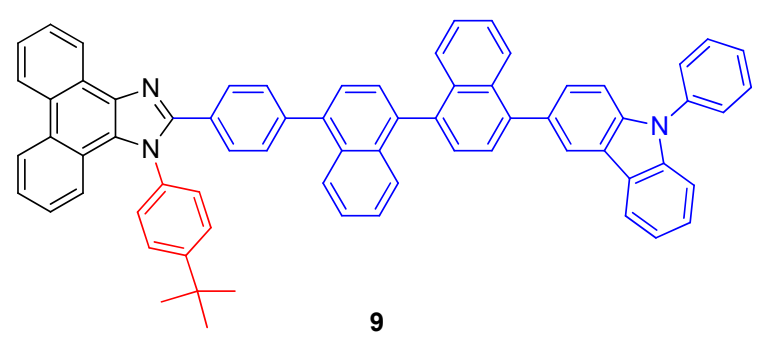

$0.084),(0.157,0.074)$, 最大外量子效率分别在 $3.38 \%$, $5.95 \%$ 和 $5.05 \%$ 左右. 值得一提的是以 8 为发光层的 20 $\mathrm{wt} \%$ 掺杂器件 ITO/NPB (70 nm)/TCTA (5 nm)/CBP +8 $(30 \mathrm{~nm}) / \mathrm{TPBi}(30 \mathrm{~nm}) / \mathrm{LiF}(1 \mathrm{~nm}) / \mathrm{Al}(100 \mathrm{~nm})$. CIE 坐标 为 $(0.153,0.059)$ 并且拥有 $(6.96 \pm 0.08) \%$ 的最大外量子效 率, 在 $1000 \mathrm{~cd} \cdot \mathrm{m}^{-2}$ 的亮度下不仅外量子效率仍然有 $(6.56 \pm 0.11) \%$, 而且 $\mathrm{CIE}_{\mathrm{y}}$ 仍小于 0.08 (NTSC 标准), 是 当时所报道的 $\mathrm{CIE}_{\mathrm{y}}$ 小于 0.08 的最高 $\mathrm{EQE}$ 器件.

2017 年, Tong 课题组 ${ }^{[46]}$ 通过在菲并咪唑 C2 和 N1 位置上引入拥有空穴传输能力的芳基胺取代基三苯胺 和菜苯胺作为给电子基团, 成功设计了两个多功能双极 性芳基胺-菲并咪唑蓝光材料 10 和 11. 由于具有合适的 拉伸电子能力及 $\mathrm{CT}$ 态和 $\mathrm{LE}$ 态能级相匹配, 使得这两个 分子的 CT 态激发态和 LE态激发态充分杂化, 产生了具 有典型 HLCT 性质的激发态, 在实现高的薄膜苂光量子 产率的同时 (10 为 $66.8 \%, 11$ 为 $68.0 \%$ ), 其做成器件时的 单线态激子利用率达到了 $66.8 \%$ 和 $68.0 \%$, 远远超过传 统苂光分子 $25 \%$ 的单线态激子利用率. 由循环伏安法测 得的分子前线轨道可以看出, 10 的 HOMO 及 LUMO 能 级为 -5.27 和 $-2.27 \mathrm{eV}, 11$ 为 -5.32 和 $-2.30 \mathrm{eV}$, 表示 作为发光层时, 其空穴注入壁垒可以忽略不计, 并且具 有作为双功能材料 (发光层十空穴传输层)的可能性. 以 10 和 11 为非掺杂器件的 OLED 发光层, 其器件结构为

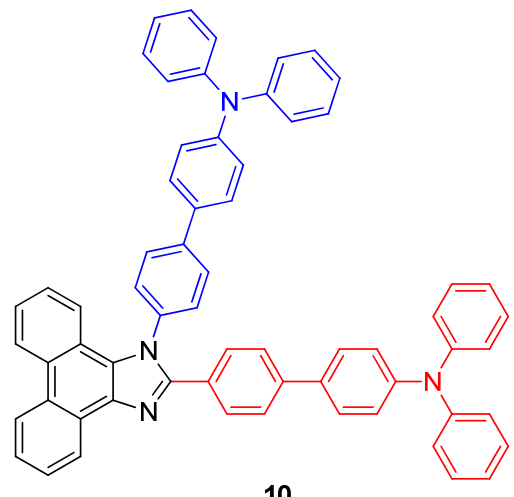

10

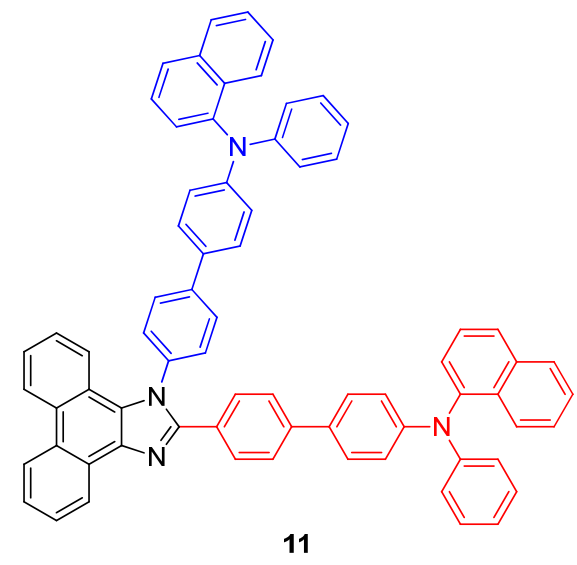


ITO/HATCN (5 nm)/NPB (60 nm)/TCTA $(5 \mathrm{~nm}) / \mathbf{1 0}$ 或 11 $(20 \mathrm{~nm}) / \mathrm{TPBi}(40 \mathrm{~nm}) / \mathrm{LiF}(1 \mathrm{~nm}) / \mathrm{Al}(100 \mathrm{~nm})$, 其中以 10 为发光层的器件表现出 $7.20 \%$ 的最大外量子产率, 其电 流效率和电源效率分别为 $4.40 \mathrm{~cd} \bullet \mathrm{A}^{-1}$ 和 $4.60 \mathrm{~lm} \bullet \mathrm{W}^{-1}$; 以 11 为发光层的器件也展现出优良的电致发光性能 $\mathrm{EQE}, \mathrm{CE}$ 和 $\mathrm{PE}$ 分别为 $6.33 \%, 3.98 \mathrm{~cd} \bullet \mathrm{A}^{-1}$ 和 $3.88 \mathrm{~lm} \bullet$ $\mathrm{W}^{-1}$, 并拥有 $18105 \mathrm{~cd} \cdot \mathrm{m}^{-2}$ 的最大亮度. 两个器件在 $1000 \mathrm{~cd} \cdot \mathrm{m}^{-2}$ 的亮度时仍然保持不错的 EQE (6.30\%和 $6.32 \%$ ), 表现出小的效率滚降. 当器件结构为 ITO/ $\mathrm{MoO}_{3}(3 \mathrm{~nm}) / \mathbf{1 0}$ 或 $11(20 \mathrm{~nm}) / \mathrm{TPBi}(30 \mathrm{~nm}) / \mathrm{LiF}(1$ $\mathrm{nm}) / \mathrm{Al}(100 \mathrm{~nm})$, 即 $\mathbf{1 0}$ 和 $\mathbf{1 1}$ 同时作为器件的发光层和 空穴传输层时, 仍然表现出不错的最大外量子效率 $4.69 \%$ 和 $4.10 \%$, 并且其色坐标接近 $(0.15,0.06)$, 满足 NTSC 对蓝光的规定.

2017 年, Tong 等 ${ }^{[47]}$ 首次将吸电子基三氟甲基引入 菲并咪唑的 N1 号位, 旨在增强分子的电子传输能力及 增加其 CT 态的组分, 氟代有机物的 $\mathrm{C}-\mathrm{H} \cdots \mathrm{F}$ 键也可以 促进材料的载流子传输能力, 同时, 为了避免双菲并咪 唑通常出现的聚集态荧光猝灭现象, 他们破坏其中一个 菲并咪唑的菲环, 同时改变其连接方式(C2 取代及 $\mathrm{N} 1$ 取代)以控制共轭的长度. 由于具有扭曲的结构及三氟 甲基的空间位阻作用, 分子 12 及 13 固态显示出细微的 红移(9 和 $18 \mathrm{~nm}$ ), 且其固态荧光量子产率分别为 $79.5 \%$ 和 $74.2 \%$. 以 12 及 13 两个分子为非掺杂器件发光层 ITO/NPB (70 nm)/TCTA (5 nm)/12 或 $13(20 \mathrm{~nm}) / \mathrm{TPBi}(40$ $\mathrm{nm}) / \mathrm{LiF}(0.8 \mathrm{~nm}) / \mathrm{Al}(80 \mathrm{~nm})$, 都表现出标准的深蓝发射, 其 CIE 坐标分别为 $(0.15,0.08)$ 和 $(0.15,0.07)$, 并且获得 $4.3 \%$ 及 $4.5 \%$ 的最大外量子产率, 由于器件的载流子传 输平衡及发光层的复合效率高, 其单线态激子利用率分

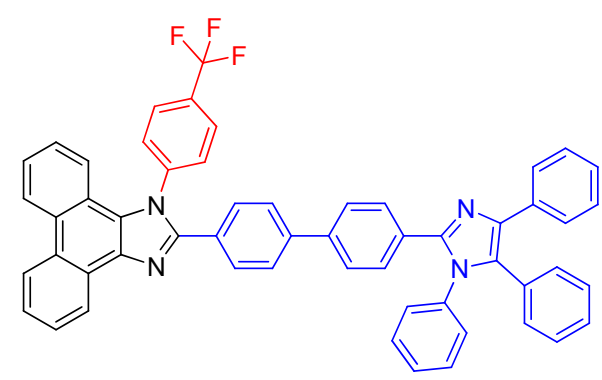

12

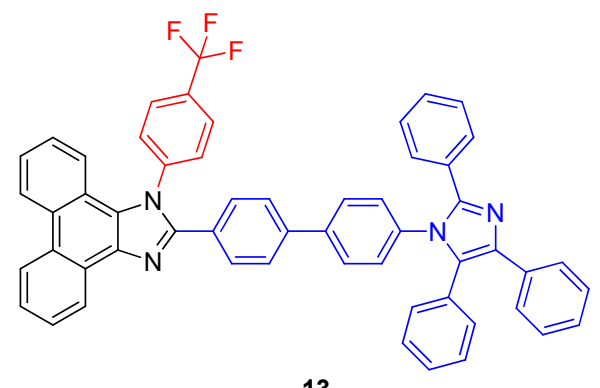

13
别达到了 $27.0 \%$ 及 $30.3 \%$.

2018 年, Lee 等 ${ }^{[48]}$ 首次将多芳基环 1,2,3,4-tetraphenylnaphthalene (TNa)引入深蓝发射材料的构建, TNa 由一个菜基及周围四个取代的苯环组成，具有很大的体 积, 由高斯计算得出 $\mathrm{TNa}$ 的分子前线轨道 $\mathrm{HOMO}$ 和 LUMO 分别为 -5.54 和 $-1.11 \mathrm{eV}$ ，由 $\mathrm{TNa}$ 和菲并咪坐的 结合，通过调整二者之间的共轭长度，成功合成出三个 蓝色发射的分子 $14 \sim 16$ ，三个分子都表现出不错的热 稳定性及优秀的苂光量子产率。通过密度泛函(TDDFT) 一系列理论计算，阐明 $\mathrm{TNa}$ 在三个分子中担任电 子受体的角色，三个分子在薄膜时都为深蓝色发射，并 且显示出良好的双极性传输性质, 电子传输性能明显好 于空穴传输性能, 以 16 为发光层的非掺杂器件 ITO/NPB (70 nm)/TCTA (5 nm)/16 (25 nm)/TPBi (40 $\mathrm{nm}) / \mathrm{LiF}(1 \mathrm{~nm}) / \mathrm{Al}(150 \mathrm{~nm})$ 表现出优越的电致发光性能, 伴随着 $5.78 \%$ 的最大外量子效率及 $\mathrm{CIE}$ 坐标为 $(0.152$, $0.085)$ 的深蓝色发射. 除此以外, 以 $30 \mathrm{wt} \%$ 掺杂的 14 为 发光层的器件显示出 CIE 坐标为 $(0.156,0.043)$ 的紫蓝色 发射，在亮度为 $1000 \mathrm{~cd} \cdot \mathrm{m}^{-2}$ 时仍然拥有 $2.52 \%$ 的 EQE.
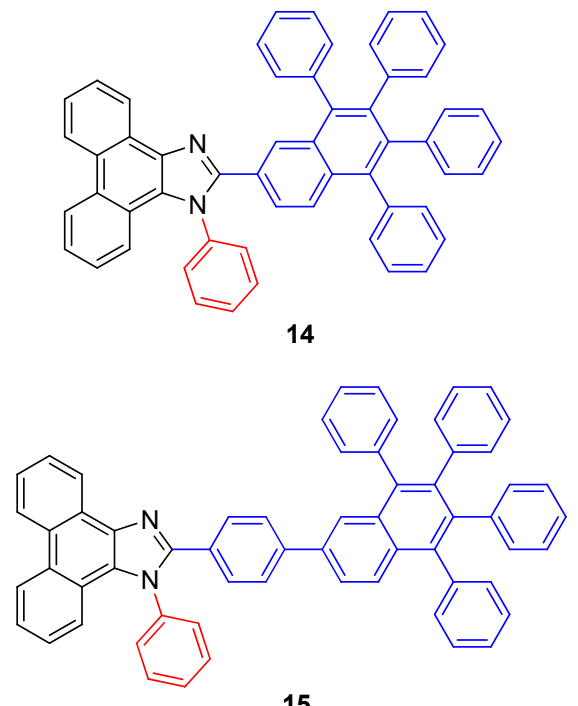

15

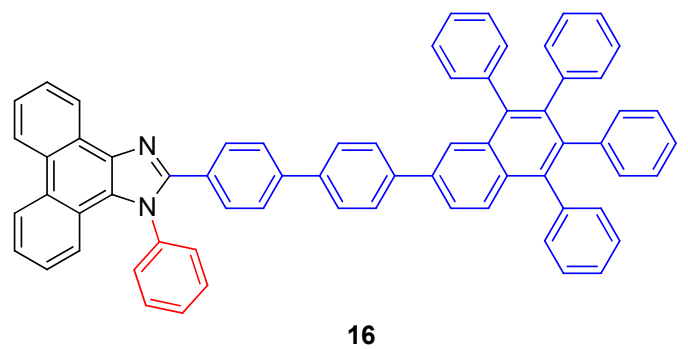

Liu 等 ${ }^{[39]}$ 成功地合成了两种基于由咔唑、苯并咪唑 和氰基的具有 D-A 结构的蓝色苂光分子 17 和 18 . 由于 具有扭曲的结构(氰基与相邻的苯环近乎垂直)及咪唑和 咔唑之间桥联长度的增加(3.64 ̊̊), 尽管相邻两个平行 菲并咪唑基团具有一定程度上的重叠, 但是由于给体咔 
唑及受体菲并咪唑之间共轭长度的延长 $(4.32 \AA), \mathbf{1 8}$ 比 17 具有更短的发射波长、更高的 PLQY 和更好的热稳 定性. 基于 18 的非掺杂装置 $\mathrm{ITO} / \mathrm{MoO}_{3} \quad(2$ nm)/TCTA: $\mathrm{MoO}_{3}(20 \mathrm{wt} \%, 40 \mathrm{~nm}) / \mathrm{TCTA}(10 \mathrm{~nm}) / 18$ (20 $\mathrm{nm}) / \mathrm{TPBi}(40 \mathrm{~nm}) / \mathrm{LiF}(1 \mathrm{~nm}) / \mathrm{Al}(100 \mathrm{~nm})$ 在显示深蓝发 射, CIE 坐标 $(0.15,0.08)$ 非常接近 NTSC 标准的同时. 其 $\mathrm{EQE}$ 最大值为 $4.71 \%$, 而且显示出相当小的效率滚降 (在 $1000 \mathrm{~cd} \cdot \mathrm{m}^{-1}$ 上同比下降了 $3.2 \%$ ). 通过进一步优化 了空穴输送层[将 TCTA: $\mathrm{MoO}_{3}(20 \mathrm{wt} \%, 40 \mathrm{~nm}) / \mathrm{TCTA}$ $(10 \mathrm{~nm})$ 换为 TCTA: $\mathrm{MoO}_{3}(20 \mathrm{wt} \%, 20 \mathrm{~nm}) /$ TCTA $(40$ $\mathrm{nm})$ ], 该非掺杂器件可获得 5.80\%的 $\mathrm{EQE}$ 最大值.

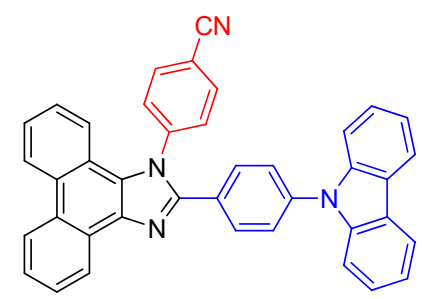

17

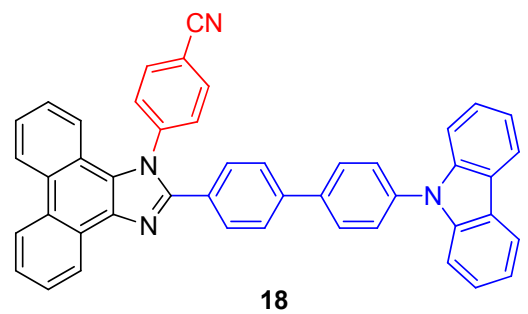

18

2018 年, Lee 等 ${ }^{[49]}$ 通过在菲并咪唑的 N1 位置上引 入一个具有 $n$-type 的取代基 TPPO (triphenyl-phosphine), 由于 $\mathrm{TPPO}$ 本身拥有卓越的电子注入和电子传输能力, 是构筑电子传输材料及主体材料常用的基团之一. 但是 由于其自身过于强的吸电子能力会导致分子色纯度的 不足, 和 P 原子上共轭结构的破坏可能会导致荧光量子 产率的下降, 使其很少运用于构建蓝光发光材料中. Lee 等利用其特性, 将其引入 N1 位置上, 使它和菲并咪唑 之间形成一个近乎垂直的二面角, 这样扭曲的结构可以 充分抑制分子内电荷转移现象, 结果使分子的发射集中 到菲并咪唑和 $\mathrm{C} 2$ 取代基的基团上, 增强了分子的电子 传输能力. 通过 $\mathrm{C} 2$ 位置引入不同的给电子基团, 得到 一个深蓝发射的 19 和两个近紫外发射的 20 和 21 . 基于 20 和 21 非掺杂器件 ITO/NPB $(65 \mathrm{~nm}) / \operatorname{TCTA}(5 \mathrm{~nm}) / \mathbf{2 0}$ 或 $21(25 \mathrm{~nm}) / \mathrm{TPBi}(30 \mathrm{~nm}) / \mathrm{LiF}(1 \mathrm{~nm}) / \mathrm{Al}(120 \mathrm{~nm})$ 的 $\mathrm{EQE}_{\text {max }}$ 可以达到 $5.08 \%$ 和 $4.42 \%$, 它们的 CIE 坐标分别 为 $(0.156,0.061)$ 和 $(0.157,0.071)$, 当他们掺杂在 $\mathrm{CBP}$ 时, 显示出相同的外量子效率及更蓝的发射 $\left(20\right.$ 的 $\mathrm{CIE}_{y}=$ $0.050,21$ 的 $\mathrm{CIE}_{y}=0.044$ ). 基于 19 的非掺杂器件显示出 更为卓越的性能, $\mathrm{EQE}_{\text {max }}=6.69 \%, \mathrm{CIE}$ 为 $(0.152,0.095)$,
以其为主体材料掺杂了黄色磷光材料的 OLED 器件, ITO/NPB $(65 \mathrm{~nm}) /$ TCTA $(5 \mathrm{~nm}) / \mathbf{1 9}(10 \mathrm{~nm}) / \mathbf{1 9}$ : 客体(5 $\mathrm{wt} \% 15 \mathrm{~nm}) / \mathrm{TPBi}(30 \mathrm{~nm}) / \mathrm{LiF}(1 \mathrm{~nm}) / \mathrm{Al}(120 \mathrm{~nm})$ 得到了 最大 $\mathrm{EQE}$ 为 $20.3 \%$ 的白光 OLED, 其在亮度为 1000 $\mathrm{cd} \cdot \mathrm{m}^{-2}$ 时启动电压低至 $3.2 \mathrm{~V}$. 同时 19 是一个不错的双 极性材料, 以 $\mathrm{ITO} / \mathrm{MoO}_{3}(3 \mathrm{~nm}) / \mathbf{1 9}(70 \mathrm{~nm}) / \mathbf{1 9}$ : 客体 (5 $\mathrm{wt} \%, 50 \mathrm{~nm}) / \mathrm{LiF}(1 \mathrm{~nm}) / \mathrm{Al}(120 \mathrm{~nm})$ 为器件得到 $\mathrm{EQE}$, $\mathrm{CE}$ 和 $\mathrm{PE}$ 分别为 $12.9 \%, 36.1 \mathrm{~cd} \bullet \mathrm{A}^{-1}$ 和 $30.5 \mathrm{~lm} \cdot \mathrm{W}^{-1}$.
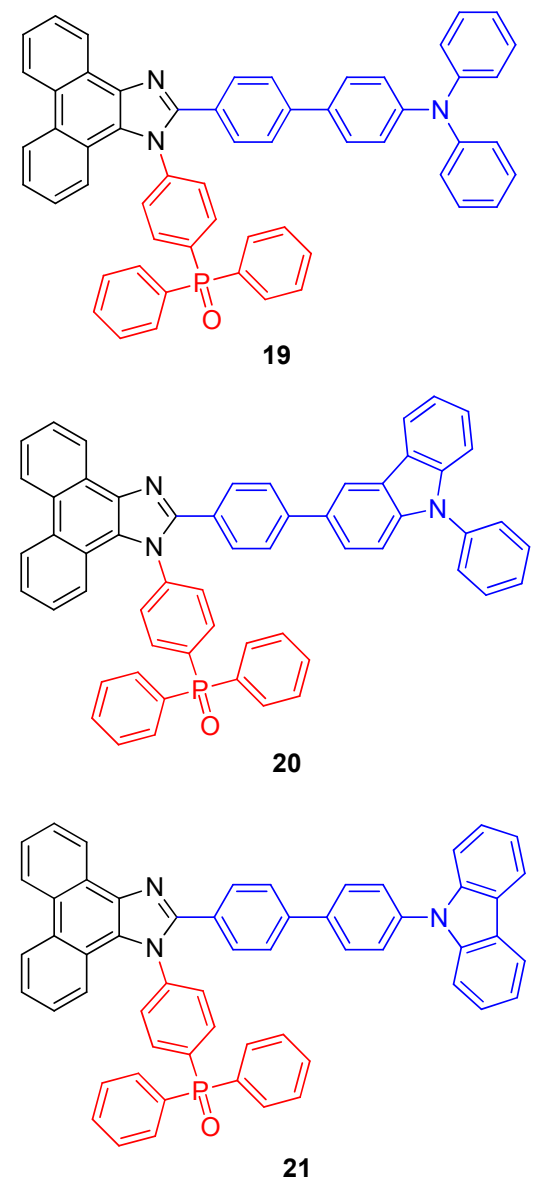

2018 年, Zhang 等 ${ }^{[50]}$ 将吲哚嗪和菲并咪唑相结合, 菲并咪唑作为给体, 吲哚嗪作为受体, 通过在供受体之 间的苯环上加入甲基改变菲并咪唑与吲哚嗪之间的共 轭程度及取代位置, 设计合成了三个蓝光分子 $\mathbf{2 2} \sim \mathbf{2 4}$. 由吲哚嗪的氮杂环共轭结构, 实现高的荧光量子产率, 并且其自身优秀的电荷传输能力, 可以促进其作为器件 发光层的电致发光效率. 结果表明, 通过引入甲基增加 其位阻可以使光谱蓝移(薄膜发射蓝移 $38 \mathrm{~nm}$ ), 但是由 于扭曲的结构会导致载流子能力的下降. 通过激发态偶 极矩的计算, 这三个分子都拥有局域杂化-电荷转移激 发态的特性. 以 $22 \sim 24$ 三个分子为发光层构筑的器件, ITO/ $\mathrm{MoO}_{3}(1 \mathrm{~nm}) /$ TAPC $(70 \mathrm{~nm}) /$ TCTA $(7 \mathrm{~nm}) / \mathbf{2 2} \sim \mathbf{2 4}$ $(20 \mathrm{~nm}) / \mathrm{TPBi}(40 \mathrm{~nm}) / \mathrm{LiF}(0.8 \mathrm{~nm}) / \mathrm{Al}(80 \mathrm{~nm})$ 实现 $(0.150,0.092),(0.152,0.057),(0.154,0.058)$ 的色坐标, 可 
以达到 17100,9163 和 $9165 \mathrm{~cd} \bullet \mathrm{m}^{-2}$ 的最大亮度, $\mathrm{EQE}$ 分 别为 $4.95 \%, 4.51 \%$ 和 $4.60 \%$. 将发光层改为 $\mathrm{CBP} / 40 \mathrm{wt} \%$ 22, 其拥有最大亮度 $14350 \mathrm{~cd} \cdot \mathrm{m}^{-2}$, 和 6.01 的外量子效 率. 值得一提的是, 所有的器件设备都表现出外量子产 率随着亮度增大而上升的趋势. 特别是基于 22 的器件 在 $14350 \mathrm{~cd} \cdot \mathrm{m}^{-2}$ 的超高亮度情况下仍然拥有超过 $6 \%$ 的 外量子产率, 这在深蓝发射的苂光或是热激活延迟苂光 材料都是极为少见的.

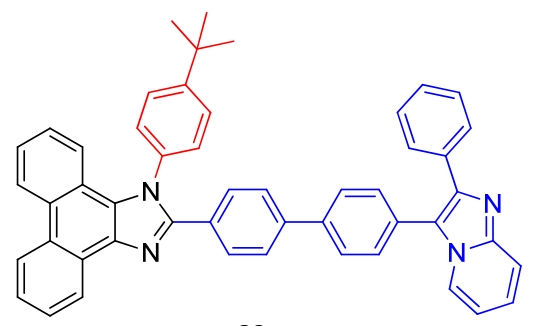

22

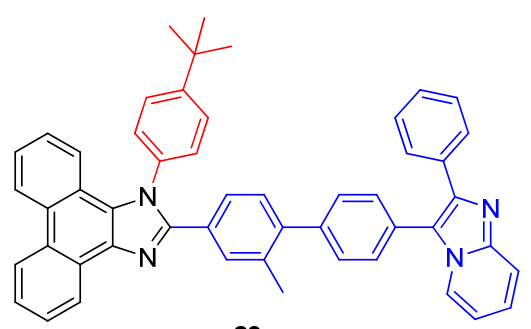

23

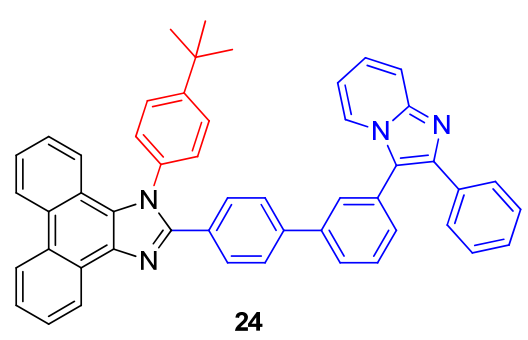

\section{2 基于 TTA 原理的 D-ா-A 型菲并咪唑衍生物}

利用三重态-三重态湮灭上转换(Triplet-Triplet Annihilation, TTA)的原理也成为发展蓝光 OLED 器件的一 种分子设计方式, TTA 延迟荧光是通过利用两个三重态 的激子碰撞湮灭产生一个单重态激子辐射跃迁回到基 态, 发出荧光和一个非辐射跃迁回到基态的激子, 理论 上能达到的最大内量子效率为 $62.5 \%(25 \%+37.5 \%)$, 远 远超过了传统苂光材料器件 $25 \%$ 的限制, 大大增强了苂 光分子的内量子效率 ${ }^{[51,52]}$. 由于高的电流密度可以促进 三重态激子之间的碰撞，从而促进单线态激子的生成， 导致运用 TTA 原理设计的分子器件在高的电流密度下 仍然可以保持高的量子产率 ${ }^{[3,54]}$. 同时, 这样独特的激 子作用使其在非掺杂器件中较磷光材料器件及热活化 延迟苂光器件易于拥有更好的色纯度及更好的器件性 能. 但是由于种种原因, TTA 分子此前常需要掺杂在主 体材料中, 从而取得更好的器件性能 ${ }^{[5,56]}$.
自 TTA 运用在 OLED器件以来, 许多科研工作者将 分子设计的目光投注在多苯环基团如葱 ${ }^{\left[{ }^{[} 7\right]}$ 及萠 ${ }^{[55,58]}$ 上, 因为其三线态能级与单线态能级之间的关系 $2 E_{\mathrm{T} 1}>E_{\mathrm{S} 1}$, 使三线态激子更容易通过 TTA 过程转化为单线态激子.

2017 年, $\mathrm{Lu}$ 等 ${ }^{[59]}$ 在菲并咪唑 $\mathrm{C} 2$ 取代基上引入芳基 取代基萗、葱、芘, 得到 3 个菲并咪唑衍生物 $\mathbf{2 5} \sim \mathbf{2 7}$, 以 探寻不同苯环个数的取代基对 TTA 过程的影响. 由低 温瞬态寿命结果表明, 最低激发三重态主要位于葱及萠 取代基，使得两个分子的 $2 E_{\mathrm{T} 1}>E_{\mathrm{S} 1}$, 具有 $\mathrm{TTA}$ 过程的 可能. 以器件结构的非掺杂 OLED:ITO/HATCN (6 $\mathrm{nm}) /$ TAPC $(x \mathrm{~nm}) /$ TCTA $(y \mathrm{~nm}) / \mathbf{2 5} \sim \mathbf{2 7}(20 \mathrm{~nm}) /$ TPBi $(z$ $\mathrm{nm}) / \mathrm{LiF}(1.2 \mathrm{~nm}) / \mathrm{Al}(120 \mathrm{~nm})$, 由 $\mathbf{2 6}$ 及 $\mathbf{2 7}$ 的器件一开始 器件亮度与电流密度成二次指数关系, 表明其器件具有 TTA 过程, 测试结果表明 26 器件的单线态激子利用率 为 36\% 45\%, 证明了 TTA 过程对提升器件单线态激子 率具有重要作用. 基于 26 的非掺杂器件色坐标为 $(0.15$, $0.14)$, 亮度在 $100 \sim 1000 \mathrm{~cd} \cdot \mathrm{m}^{-2}$ 时的外量子产率在 $4.57 \% \sim 5.11 \%$ 之间，在 $10000 \mathrm{~cd} \cdot \mathrm{m}^{-2}$ 的亮度时仍然能 保持 $4.76 \%$ 的外量子产率, 并且拥有 $54300 \mathrm{~cd} \cdot \mathrm{m}^{-2}$ 的 最大亮度, 表明基于 TTA 原理的 OLED 器件具有很大的 发展潜力。

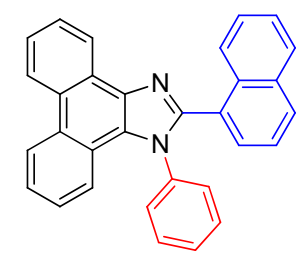

25

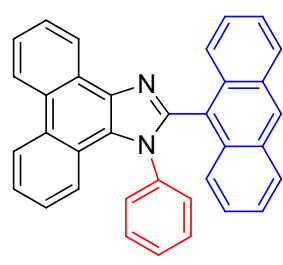

26

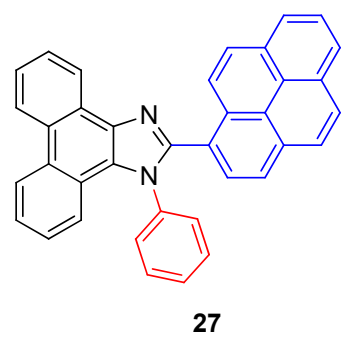

次年, $\mathrm{Lu}$ 等 ${ }^{[60]}$ 报道了以葱为桥联的菲并咪唑衍生 物 28, 通过利用葱基团最低单线态和三线态能级差较 大的本质，实现了三重态-三重态湮灭上转换过程，以 28 作为非掺杂器件 ITO/HATCN (6 nm)/TAPC (25 $\mathrm{nm}) / \mathrm{TCTA}(15 \mathrm{~nm}) / \mathbf{2 8}(20 \mathrm{~nm}) / \mathrm{TPBi}(40 \mathrm{~nm}) / \mathrm{LiF}(0.5$ $\mathrm{nm}) / \mathrm{Al}(120 \mathrm{~nm})$ (图 5)的最大外量子效率可以达到 $9.44 \%, \mathrm{CIE}$ 坐标为 $(0.14,0.19)$, 并且其高亮度 $(10000 \mathrm{~cd} \cdot$ $\mathrm{m}^{-2}$ ) 时的外量子效率仍然能达到 $8.09 \%$, 展示出了较低 的效率滚降. 对比没有引入氰基的 $\mathbf{2 6}$, 相同器件结构 下, 26 的器件最大外量子产率只有 $4.20 \%$, 并且通过瞬 
态苂光的延迟组分可以看出, 以 28 为发光层的器件延 迟组分明显大于 26, 证明通过引入氧基可以增强分子 间的相互作用力, 增强 TTA 的过程, 并使得分子的 LUMO 能级降低, 降低了电子注入的势垒, 促进载流子 之间的平衡, 使得器件的构筑更加容易.
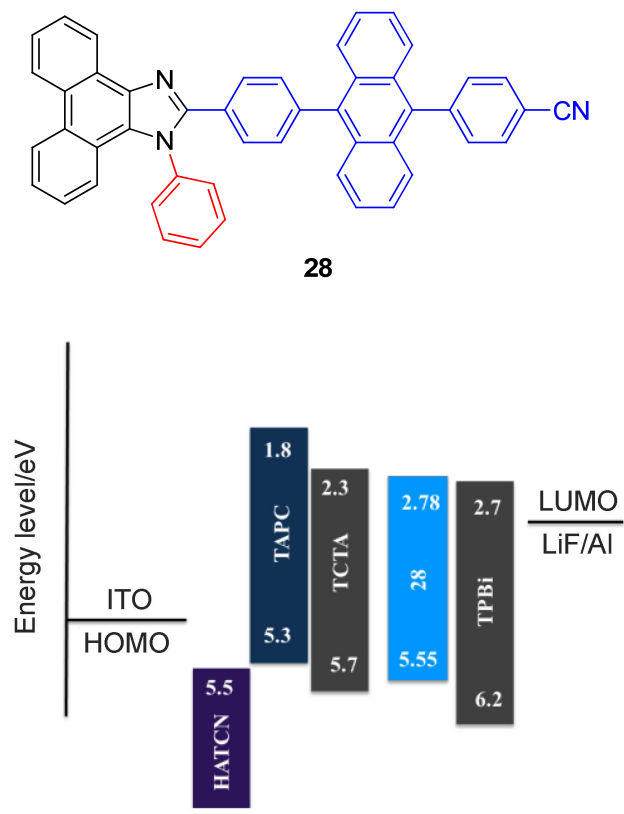

图 528 的电致发光器件及其电子能级图

Figure 5 EL structures and electronic level configurations of the devices $\mathbf{2 8}$

\section{3 基于热活化延迟荧光原理的 D-T-A 型菲并咪唑衍 生物}

根据自旋统计定理 ${ }^{[61]}$, 电激发电子按 $1: 3$ 的比例 分别产生单重态和三重态激子(即分别占 $25 \%$ 和 $75 \%$ ), 而量子力学理论的选择规则指出, 只有当两个电子态具 有相同自旋多重性时才能实现相互转换, 而具有不同自 旋多重性的两个电子态之间的跃迁是被禁阻的，一般情 况下, 基态为自旋单重态 $\left(S_{0}\right)$. 因此, 不难发现, 传统荧 光 OLED 仅仅利用 $25 \%$ 的最低激发单重态 $\left(S_{1}\right.$ 态 $)$ 电致激 子发光, $75 \%$ 的最低激发三重态 $\left(T_{1}\right.$ 态) 电致激子由于自 旋禁阻作用, 以非辐射跃迁的形式回到 $S_{0}$ 态造成损失. 因此, 传统荧光 OLED 的内量子效率(internal quantum efficiency, IQE)仅有 $25 \%$, 而遵循朗伯发光模式的苂光 OLED 器件的光取出效率只有 $20 \%$ 左右, 所以传统荧光 OLED 器件的最大外量子效率只有 $5 \%{ }^{[62]}$.

热活化延迟苂光(thermally activated delayed fluorescence, TADF) ${ }^{[63,64]}$ 材料由于自身 $S_{1}$ 与 $T_{1}$ 之间小的能级 差 $\left(\Delta E_{\mathrm{ST}}<0.5 \mathrm{eV}\right)$, 当材料被光激发, 分子内部可以发 生反向系间鼌越(reverse intersystem crossing, RISC)过 程, $T_{1}$ 态激子吸收环境热量转换到 $S_{1}$ 态, 并通过辐射跃 迁的形式发生微妙甚至毫秒级别的延迟苂光. 由于可以
充分利用剩下 $75 \%$ 的三线态激子理论上实现 $100 \%$ 的内 量子效率 $(25 \%+75 \%)$, TADF 材料是当前蓝光 OLED 研 究的热点 ${ }^{[55]}$, 但是由于菲并咪唑本身最低激发单重态 和最低激发三重态之间过大的能级差，很难实现用菲并 咪唑基团构建 TADF 分子.

2018 年, Wang 等 ${ }^{[66]}$ 利用 $\Delta E_{\mathrm{ST}}$ 只有 $0.11 \mathrm{eV}$ 并具有 典型 TADF 性质的给电子基团吩嗪作为供体，菲并咪唑 作为受体, 成功构造了两个 TADF 分子 $\mathbf{2 9}$ 和 $\mathbf{3 0}$. 得益于 分子中菲并咪唑和桥联的苯环之间近乎垂直的二面角, 可以实现 HOMO 和 LUMO 之间有效分离, 减少 $\Delta E_{\mathrm{ST}}$, 分子内 $\mathrm{C}-\mathrm{H}$ 的 $\pi$ 键可以抑制分子旋转并且抑制非辐射 跃迁. 29 和 30 的 $\Delta E_{\mathrm{ST}}$ 降低到 0.01 和 $0.008 \mathrm{eV}$, 满足 $\mathrm{TADF}$ 的能隙差. 而且 30 的苂光量子产率高达 0.99 , 以 这两个分子构筑的掺杂器件 $\mathrm{ITO} / \mathrm{MoO}_{3}(10 \mathrm{~nm}) / \mathrm{TAPC}$ $(80 \mathrm{~nm}) / \mathrm{TCTA}(10 \mathrm{~nm}) / \mathbf{2 9}$ 或 $30(30 \mathrm{~nm}) / \mathrm{TmPyPB}(40$ $\mathrm{nm}) / \mathrm{LiF}(1 \mathrm{~nm}) / \mathrm{Al}(100 \mathrm{~nm})$ (图 6)的最大外量子效率, 电 源效率和电流效率分别为 $20.52 \%, 65.90 \mathrm{~cd} \cdot \mathrm{A}^{-1}$ 和 68.98 $1 \mathrm{~m} \bullet \mathrm{W}^{-1}$, 以及 $21.06 \%, 67.18 \mathrm{~cd} \bullet \mathrm{A}^{-1}, 68.11 \mathrm{~lm} \bullet \mathrm{W}^{-1}$. 虽 然得到的器件为绿光发射, 但是为构建深蓝发射 OLED 的 TADF 分子提供一个潜在的设计思路.

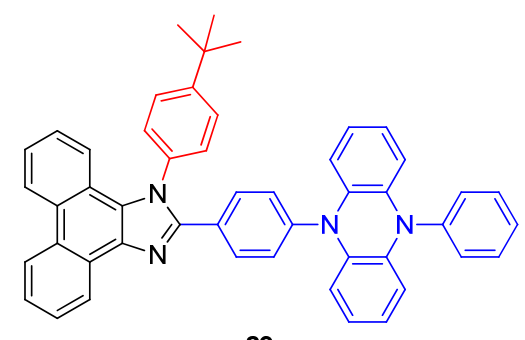

29

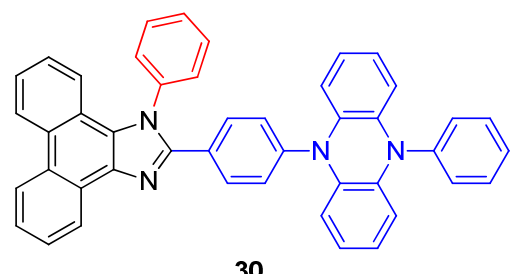

30

\section{4 基于 LEC 原理的 D-T-A 型菲并咪唑衍生物}

聚合物发光电化学池(Polymer Light-emitting Electrochemical Cell, LEC) 是依据聚合物发光二极管的发光 特性，通过在聚合物发光层中掺入固体聚合物电解质制 备出来的 ${ }^{[67]}$. 对比其他固态发光器件, 简易单层的器件 结构与较低的制作成本, 再加上空气环境下便能制备器 件使其具备一定的优势 ${ }^{[68,69]}$. 其发光层的主要材料为共 轭聚合物或离子过渡金属配合物。

菲并咪唑作为一个优秀的蓝光材料构筑基团，在 LEC 研究方面也受到科研工作者的关注. 早在 2015 年, Choe 等 ${ }^{[70]}$ 将菲并咪唑衍生物引入 $\mathrm{LEC}$ 的发光层, 设计 


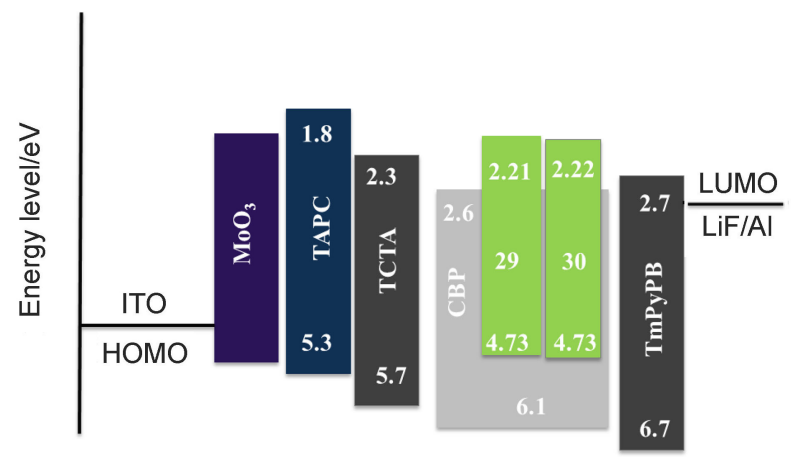

图 $628 / 29$ 的电致发光器件及其电子能级图

Figure 6 EL structures and electronic level configurations of the devices $\mathbf{2 8} / \mathbf{2 9}$

合成一个萠在 $\mathrm{C} 2$ 位置取代的菲并咪唑衍生物 31, 并以 此构筑 LEC 器件. 器件结构为 ITO/PEDOT:PSS $(80 \mathrm{~nm}) /$ 发光层 $(90 \mathrm{~nm}) / \mathrm{Al}(100 \mathrm{~nm})$, 发光层为菲并咪唑、聚氧化 乙烯、三氟甲烷磺酸锂三组以质量分数为 $1: 0.1: 0.185$ (31: $\mathrm{PEO}: \mathrm{LiCF}_{3} \mathrm{SO}_{3}$ ) 的比例混合, 溶解在体积比为 $1: 0.57$ 的四氢呋喃和环己酮中, 在空气下以旋涂的方 式制成器件. 器件发射为 $521 \mathrm{~nm}$, 色坐标为 $(0.38,0.49)$, 虽然不是蓝光发射, 但是为 LEC 器件的发光层材料提 供一个新的设计思路. 该课题组 ${ }^{[71]}$ 在次年将其作为主 体材料制作主体-客体型 LEC 器件, 也取得不错的发光 效果.

同年，该团队 ${ }^{[72]}$ 在 31 的基础上，通过在 $\mathrm{N} 1$ 位置上 引入丁基链、己基链以及它们的离子化合物, 设计合成 了天蓝色的离子菲并咪唑衍生物 $\mathbf{3 2} \sim \mathbf{3 5}$. 四个分子在 薄膜状态时都呈现蓝色发射 459, 462, 463 和 $458 \mathrm{~nm}$, 且 离子化合物表现出较小的聚集态红移及稍高的苂光量 子产率. 以 ITO/PEDOT:PSS/发光层/Al 为器件结构(图 7), 32 和 33 与离子传输共聚物、离子盐混合作为发光层; 34 和 35 无需掺杂, 溶解性优秀的 34 作为 LEC 器件的 发光层, 获得了 $711 \mathrm{~cd} \cdot \mathrm{m}^{-2}$ 的最大亮度及 $0.18 \mathrm{~cd} \cdot \mathrm{A}^{-1}$ 的 最大电流效率, 对比 31 的器件, 亮度是其 5 倍. 32 和 33 的 LEC 器件较 31 器件亮度增大 20 倍, 证明了菲并咪唑 $\mathrm{N} 1$ 位置上的取代基对其 LEC 器件的电致发光性能有着 决定性的作用.

虽然荎和三苯胺较葱及萠具有较小的共轭长度, 但 是这类菲并咪唑衍生物用于 LEC 器件发光层存在一定 困难, 其分子过大的能级差阻碍了载流子的注入过程. 2017 年, Choe 等 ${ }^{[73]}$ 将葱及萠以邻位或间位方式连接在 菲并咪唑, 成功合成了四个深蓝发射的离子菲并咪唑衍 生物 36 39. 结果表明邻位取代较间位取代具有更蓝 的发射. 36 随着溶液极性上升发射光谱明显红移, 表现 出典型 $\mathrm{CT}$ 态特征, 而邻位取代的 $\mathbf{3 8}$ 由于扭曲的结构呈 现出更多的 LE 态组分. 因为邻位取代的 38 和 39 在

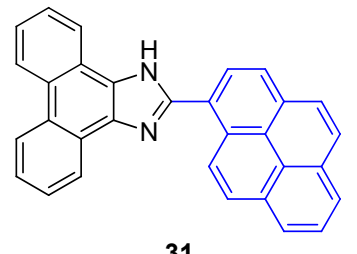

31

$$
33: R=\text { butyl }
$$
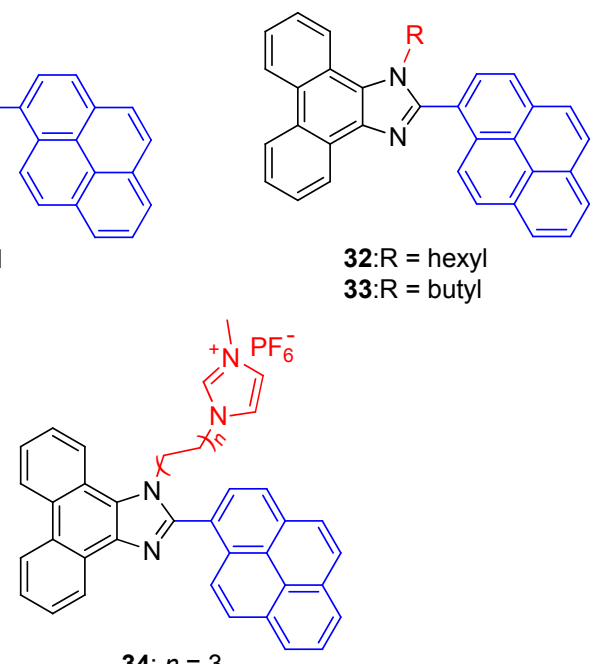

32: $R=$ hexyl

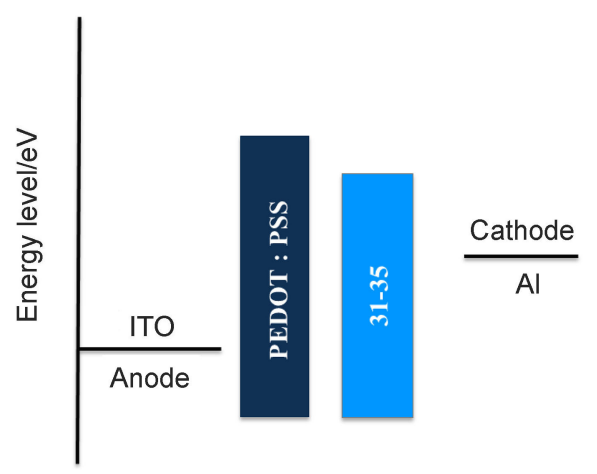

图 $731 \sim 35$ 的电致发光器件结构图

Figure 7 EL structures and e of the devices $31 \sim 35$

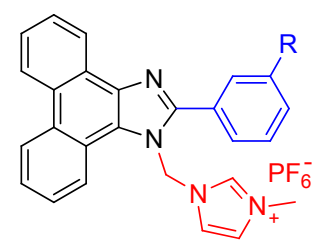

$36 \mathrm{R}=\mathrm{Py}$

$37 \mathrm{R}=\mathrm{An}$<smiles></smiles>

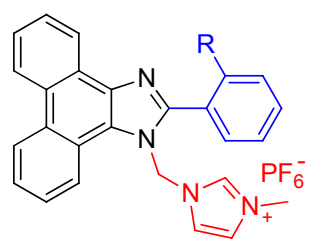

$38 \mathrm{R}=\mathrm{Py}$

$39 \mathrm{R}=\mathrm{An}$
有机溶剂溶解性不佳, 不仅无法得出光谱, 且影响其在 LEC 器件当中的运用, 无法制作成 LEC 器件. 以 $\mathbf{3 6}$ 和 37 两个分子为 LEC 器件发光层的器件结构为 ITO/PEDOT:PSS $(80 \mathrm{~nm}) /$ 发光层 $(60 \mathrm{~nm}) / \mathrm{Al}(100 \mathrm{~nm})$, 发射波长为 $485 \mathrm{~nm}$ 和 $467 \mathrm{~nm}$, 最大亮度为 179 和 26 $\mathrm{cd} \cdot \mathrm{m}^{-2}$, 对比此前报道的 35 已经获得更蓝的发射. 由于 36 具有更好的性能, 作者又以其与聚氧化乙烯和三氟 甲磺酸锂混合作为发光层, 当其比例为 $1: 0.1: 0.15$ 时 
获得最大的器件亮度 $585 \mathrm{~cd} \cdot \mathrm{m}^{-2}$. 上述器件的 $\mathrm{CIE}_{x}$ 都十 分接近 NTSC 规定的 CIE 坐标 $(0.14,0.08)$.

\section{5 其他类型的 D-T-A 型菲并咪唑衍生物}

为了抑制 $\pi-\pi$ 堆积作用而引起的聚集态荧光猝灭, 常用的方法是引入具有聚集诱导发光 (aggregation-induced emission, AIE)效应的基团 ${ }^{[74]}$ (如四苯乙烯等), 四 苯乙烯作为一类典型的取代苯乙烯类化合物, 由于分子 中含有较大的共轭体系, 因此表现出许多独特的光学性 质 ${ }^{[75]}$. 四苯乙烯在溶解的状态时, 由于分子中四个苯环 均能自由转动而导致分子的激发态能量有所降低, 使化 合物的发光微弱. 而在聚集状态下, 分子的构象发生了 变化, 苯环的自由转动受到限制, 抑制了非辐射衰减的 能力, 从而使分子的苂光效应增强 ${ }^{[2]}$. 四苯乙烯是一种 典型的具有 AIE 效应的苂光团 ${ }^{[76]}$, 且该类衍生物由于具 有发光性能优良、官能团易于修饰等优点而被广泛地应 用于各个领域. 具有 AIE 效应的化合物表现为, 在溶解 状态下无荧光现象, 而在聚集状态下却能发出很强的苂 光响应, 可以有效地解决传统苂光材料在固态聚集态时 由于 $\pi-\pi$ 堆积所造成的聚集淬灭问题 $[77,78]$.

2017 年, Misra 等 ${ }^{[79]}$ 将四苯乙烯引入菲并咪唑 C2 位 置苯环上的邻、间、对位, 合成了三个具有 AIE 效应的 蓝光分子 40 42, 并探究不同位置取代对其 AIE 性质、 力致变色及电致发光性质的影响. 结果看出, 不同位置 取代时, 分子具有不同共轭长度及平面结构, 导致它们 光物理性质的差异. 从邻位取代到间位取代, 由于四苯 乙烯与菲并咪唑之间的扭曲程度减少, 其共轭程度增 大. 三个分子都具有可恢复的力致变色性质, 当研磨时 发射由蓝色变为绿色. 邻位及间位取代时红移了 $98 \mathrm{~nm}$, 对位取代红移 $43 \mathrm{~nm}$, 证明邻间位取代较对位取代更有 利于力致变色, 展现出了明显的 AIE 效应. 经过单层器 件测试, 邻位取代分子较其他两个具有更加优秀的载流 子传输能力, 由三个分子作为发光层的非掺杂器件, 最 大外量子产率分别为 $4.0 \% 、 2.4 \% 、 3.2 \%$, 色坐标分别为 $(0.199,0.332),(0.212,0.372)$ 和 $(0.215,0.313)$, 都为天蓝 色发射.

2018 年, Misra 等 ${ }^{[80]}$ 将四苯乙烯基团和三苯胺基团 引入菲并咪唑中, 合成了两个具有 AIE 效应和力致变色 性质的菲并咪唑衍生物 $\mathbf{4 3}$ 和 $\mathbf{4 4}$. 两个分子在四氢呋喃 溶液都展现出了深蓝的发射 $(413 \mathrm{~nm})$, 在水一四氢呋喃 溶液体系中验证它们的 AIE 效应, 结果表明随着水比例 的上升, 两个分子的荧光光谱都有显著的红移及荧光强 度呈倍数增长. 并且发现两个分子都具有力致变色的特 性, 粉末状态下研磨后, 43 和 44 的荧光发射峰分别由 433 和 $449 \mathrm{~nm}$ 红移至 492 及 $500 \mathrm{~nm}$, 并且重新溶解后都 可以恢复至原来的发射. 从单晶结构看出, 由于四苯乙
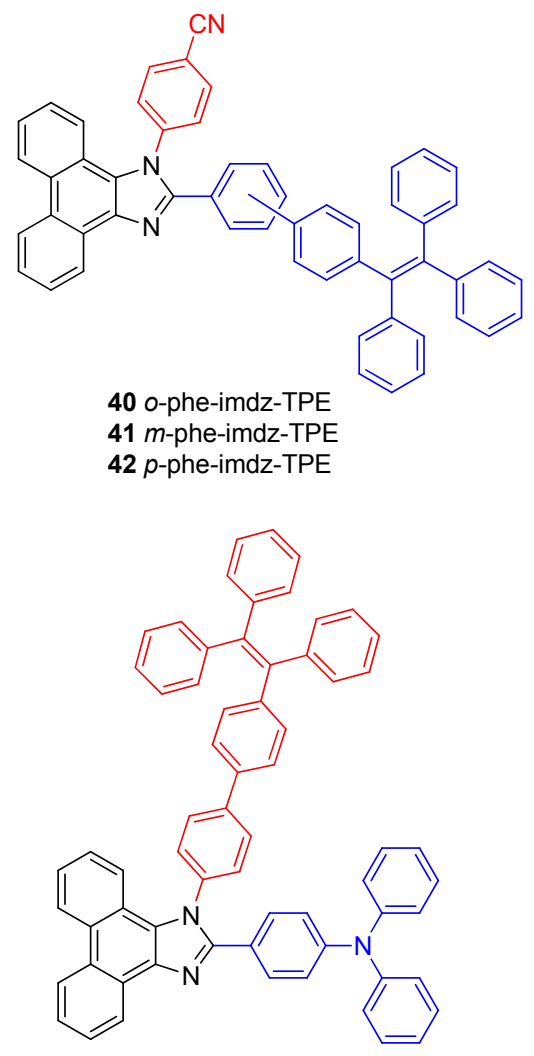

43

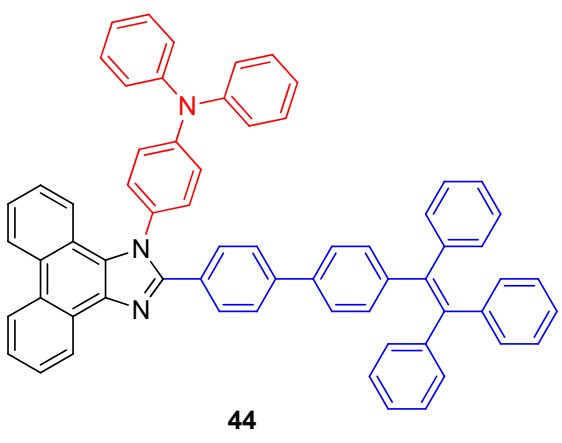

烯和三苯胺这两个扭曲基团的存在, 两个分子在晶体时 只有 $\mathrm{C}-\mathrm{H}$ 键作用而没有氢键作用和 $\pi-\pi$ 相互作用, 导 致其分子堆积松散，因而具有力致变色的特性. 以两个 分子设计的非掺杂器件的外量子效率分别达到 $2.2 \%$ 和 $4.0 \%$, 由于其自身的 AIE 效应, 两个分子在光电领域存 在进一步应用的潜力.

此外,一些砜类衍生物具有 AIE 效应的延迟苂 光 ${ }^{[81,82]}$, 同时也可以抑制聚集诱导猝灭效应. 一些分子 内作用力如 $\mathrm{C}-\mathrm{H} \cdots \pi$ 和 $\mathrm{S}=\mathrm{O} \cdots \mathrm{H}-\mathrm{C}$ 之类弱的氢键, 可以固定并使分子结构刚化, 减少分子旋转或振动, 从 而抑制分子非辐射跃迁的能力, 以实现高的苂光量子产 率. 2016 年, Tong 课题组 ${ }^{[83]}$ 以二苯砜为桥联集团, 将咔 唑和菲并咪唑衍生物作为给体连接起来, 设计了两个 $\mathrm{D}-\pi-\mathrm{A}-\pi-\mathrm{D}$ 的分子 45 和 46 . 由两个分子的单晶结构可以 看出不存在 $\pi-\pi$ 堆积现象, 两个分子在薄膜时都显示蓝 
光发射 (457 和 $458 \mathrm{~nm}$ ), 伴随着高的荧光量子产率 $(95.3 \%$ 和 $81.1 \%)$, 在粉末状态时研磨显示出可恢复的力 致变色(由白色变为黄色)和力致荧光红移(45 由 $424 \mathrm{~nm}$ 变为 $474 \mathrm{~nm}, 46$ 由 $444 \mathrm{~nm}$ 变为 $472 \mathrm{~nm}$ ). 由斯托克斯位 移与溶液极性的关系显现出两个分子都存在 HLCT 的 激发态. 以两个分子为发光层的非掺杂器件 ITO/NPB $(70 \mathrm{~nm}) /$ TCTA $(10 \mathrm{~nm}) / 45$ 或 $46(30 \mathrm{~nm}) /$ TPBI $(40$ $\mathrm{nm}) / \mathrm{LiF}(0.8 \mathrm{~nm}) / \mathrm{Al}(80 \mathrm{~nm})$ 显示出低的启动电压 $(3 \mathrm{~V}$ 左 右), 两个器件都为天蓝色发射. 以 46 为发光层的掺杂 器件 $\quad \mathrm{ITO} / \mathrm{MoO}_{3} \quad(30 \mathrm{~nm}) / \mathrm{NPB} \quad(55 \mathrm{~nm}) / \mathrm{TCTA} \quad(10$ nm)/CBP:46 (8\% wt $30 \mathrm{~nm}) / \mathrm{TmpYPB}(40 \mathrm{~nm}) / \mathrm{LiF}(0.8$ $\mathrm{nm}) / \mathrm{Al}(80 \mathrm{~nm}), \mathrm{CIE}$ 坐标为 $(0.151,0.068)$, 并且最大外 量子效率为 $5.43 \%$. 虽然电致发光效率一般, 但是也提 供了一个新的构筑菲并咪唑衍生物的思路.

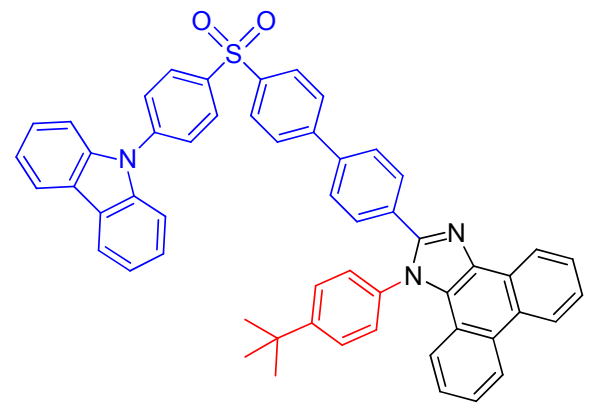

45

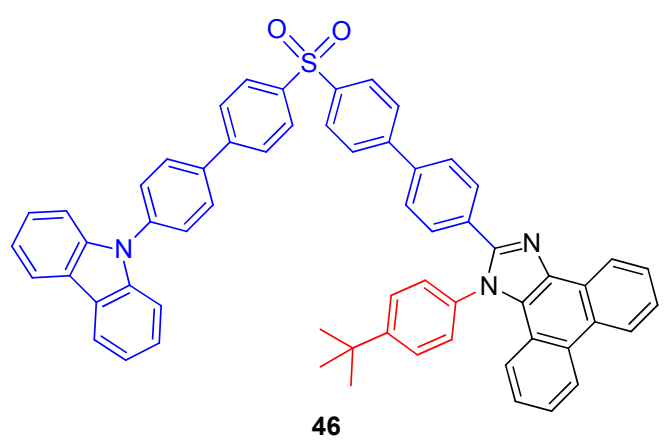

虽然 D- $\pi-A$ 类分子设计具有十分出色的性能表现， 但是此类分子设计的结构往往会导致分子内电荷转移, 也就是 ICT 现象, 导致材料的发射红移并且发射峰变 宽, 色纯度不如预期 $24,28,84,85]$. 为了保证分子前线轨道 充分地重叠, 以确保高效的共轭, 从而实现高的苂光量 子产率, 在 $\mathrm{D}-\pi-\mathrm{A}$ 类分子设计上, 许多科研工作者都采 用了对位连接的方式. 但这样做的结果会导致 $\pi$ 共轭桥 存在过大的线性长度，造成发射波长的红移并加剧 $\pi-\pi$ 堆积的作用, 同时影响了 OLED 器件时的色纯度 ${ }^{[86]}$.

为了降低分子的共轭长度并减弱分子内电荷转移 现象, 间位连接是一种常用的分子 $\pi$ 共轭桥连接类

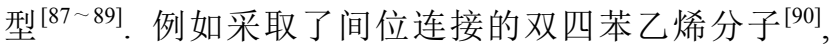
其发射波长为 $452 \mathrm{~nm}$, 比 BTPE 这个典型对位方式连接
的双四苯乙烯分子的发射峰蓝移了 $36 \mathrm{~nm}$, 证明了间位 连接方式对发射波长的调控作用.

虽然间位连接方式有其独特的优点，如使发射蓝移 和改善色纯度, 但是这种连接方式存在一个严重的缺 点, 就是会阻碍分子边界的轨道离域化, 导致 HOMO 轨 道和 LUMO 轨道无法充分重叠, 造成低的荧光量子产 率 ${ }^{[90]}$, 不利于构筑高效率的 OLED 器件.

2016 年, Tong 课题组 ${ }^{[91]}$ 以吡啶环为桥联中心, 构筑 两个 $D-\pi-A-\pi-D$ 的蓝光发射分子，采用传统对位连接方 式的 47 和采用间位连接方式的 48 . 与 47 相比，采用间 位连接的 48 具有更短的共轭长度, 并且在一定程度上 抑制了分子内电荷转移的现象. 理论计算显示，与苯环 相比, 由于氢原子的缺失，间位连接方式时吡啶环上 2 号位和 6 号位取代基具有更小的空间位阻，这导致苯 环一吡啶环一苯环架构具有大的平面可以实现更多的共 轭. 因此, 48 的分子前线轨道可以充分重叠, 并实现 $79 \%$ 的高荧光量子产率. 以两个分子作为非掺杂器件的 发光层, 其器件结构: ITO/HATCN (5 nm)/NPB (60 $\mathrm{nm}) / \mathrm{TCTA}(5 \mathrm{~nm}) / \mathbf{4 7}$ 或 48 (20 nm)/TPBI (35 nm)/LiF (1 $\mathrm{nm}) / \mathrm{Al}(120 \mathrm{~nm})$, 其中 $\mathbf{4 8}$ 为发光层的器件实现了深蓝 发射 CIE 坐标 $(0.15,0.09)$, 高的电流效率 CE $4.16 \mathrm{~cd}$ $\mathrm{A}^{-1}$ 和最大外量子效率(EQE)为 $5.15 \%$, 在一定程度上可 以謧美高效率对位器件. 此外, 还发现 48 具有作为双功 能材料的应用潜力, 制备了一个以 48 为发光层和电子 传输层的器件 ITO/HATCN (5 nm)/NPB (60 nm)/ TCTA $(5 \mathrm{~nm}) / 48(50 \mathrm{~nm}) / \mathrm{LiF}(1 \mathrm{~nm}) / \mathrm{Al}(120 \mathrm{~nm})$, 仍然呈现高的 电致发光效率 $\left(\mathrm{CE}=4.22 \mathrm{~cd} \cdot \mathrm{A}^{-1}\right.$ 和 $\left.\mathrm{EQE}=4.26 \%\right)$.

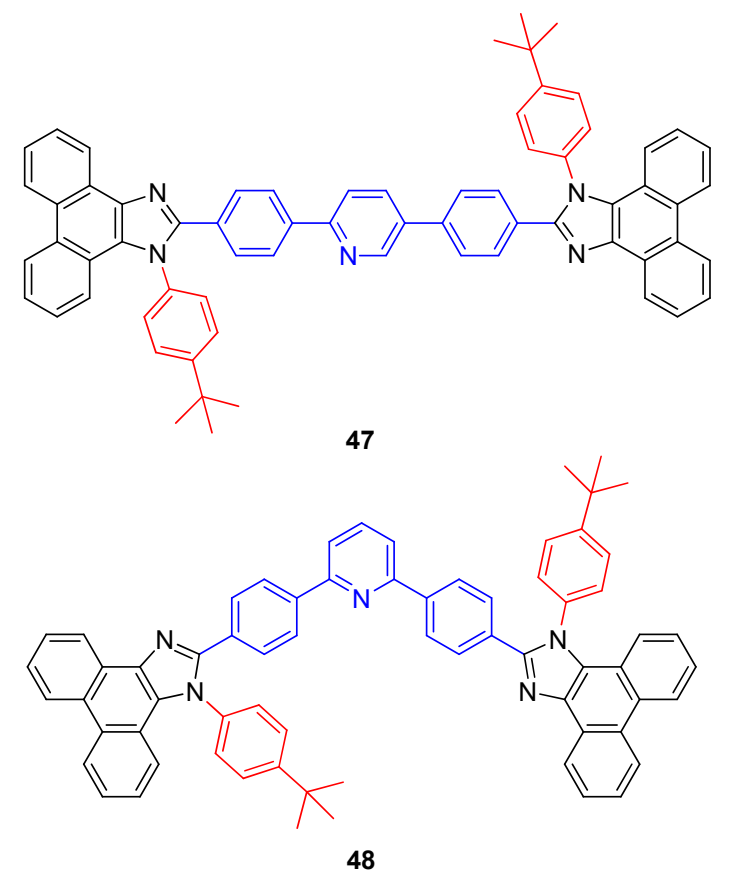

2017 年, Zhang 等 ${ }^{[92]}$ 通过引入多功能基团 CPD, 设 
计合成了分子 49 和 $\mathbf{5 0}$, 其中 $\mathrm{CN}$ 的引入增强了分子的 $\mathrm{CT}$ 态, 有利于单重态的 RISC 过程. 50 咪唑 N1 苯环上 引入叔丁基, 是为了控制分子间的距离, 避免聚集诱导 猝灭现象及提高成膜性能. 两个咪唑基团之间连接的苯 环, 形成局域激发态, 可以平衡 $\mathrm{CT}$ 态的组分, 有利于形 成高量子产率. 通过连接两个苯环增长分子间的共轭长 度, 充分抑制分子间的聚合, 有利于保持 OLED 时的高 色纯度. 49 和 50 在二氯甲烷(95\%和 89\%)和在固体时 (84\%和 $73 \%$ ) 获得很好的荧光量子产率. 以 $\mathrm{ITO} / \mathrm{MoO}_{3}$ $(10 \mathrm{~nm}) /$ TAPC $(50 \mathrm{~nm}) /$ TCTA $(7.5 \mathrm{~nm}) / 49$ 或 $\mathbf{5 0}(20$ $\mathrm{nm}) / \mathrm{TPBi}(40 \mathrm{~nm}) / \mathrm{LiF}(1 \mathrm{~nm}) / \mathrm{Al}(100 \mathrm{~nm})$ 为非掺杂器件 显示出不错的性能, $\mathrm{CE}$ 和 $\mathrm{PE}$ 及 $\mathrm{EQE}$ 分别为 $4.76 \mathrm{~cd} \cdot$ $\mathrm{A}^{-1}, 4.68 \mathrm{~lm} \cdot \mathrm{W}^{-1}$ 和 $5.07 \%$, 以 51 为发光层的器件显示 出 $3.40 \mathrm{~cd} \cdot \mathrm{A}^{-1}, 3.06 \mathrm{~lm} \cdot \mathrm{W}^{-1}$ 及 $4.20 \%$ 的最大外量子产 率, 并且分别获得了 $(0.15,0.07)$ 和 $(0.15,0.09)$ 的 CIE 坐 标. 另外他们采用一种巧妙的器件结构, 实现了一种高 效的能量传输, 提高了激子的利用率. 基于 49 的白光器 件表现出高电致发光效率, $\mathrm{CE}$ 为 $49.4 \mathrm{~cd} \cdot \mathrm{A}^{-1}, \mathrm{PE}$ 为 $1,53.5 \mathrm{~lm} \cdot \mathrm{W}^{-1}, \mathrm{EQE}$ 为 $19.0 \%$ 和 CIE 坐标 $(0.46,0.46)$. 基 于 50 同样结构的器件也显示出高的效率, 分别为 40.6 $\mathrm{cd} \cdot \mathrm{A}^{-1}, 47.2 \mathrm{~lm} \bullet \mathrm{W}^{-1}, \mathrm{EQE}$ 为 $19.4 \%$ 和 $\mathrm{CIE}$ 坐标 $(0.43$, $0.45)$.
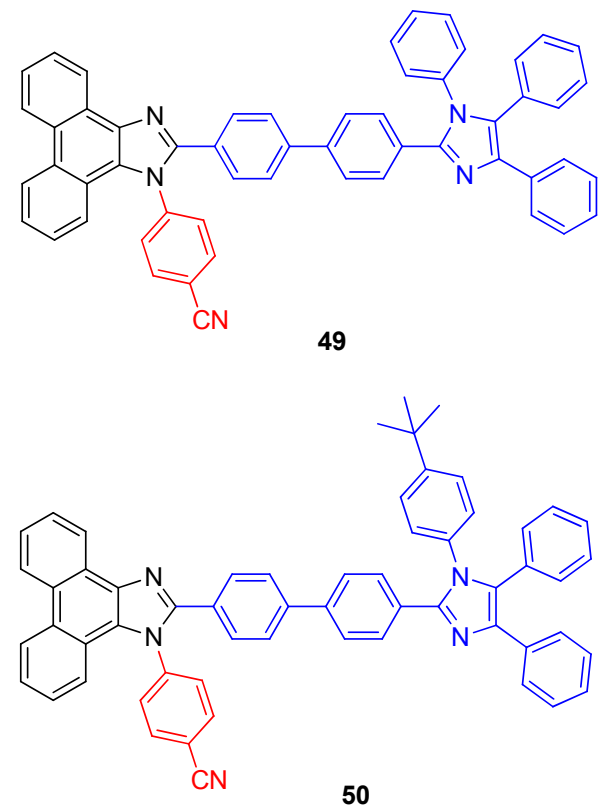

次年, 该课题组 ${ }^{\left[{ }^{[3]}\right.}$ 在菲并咪唑的 C6 和 C9 号位上引 入具有弱给电子能力的咔唑基团, 并通过咔唑的 $\mathrm{C} 3$ 号 位连接, 有效地降低了共轭长度, 削弱分子内电荷转移 现象, 保证发射的色纯度. 基于 $\mathbf{5 1}$ 的无掺杂装置 ITO/ (NPB, $70 \mathrm{~nm}) / \mathrm{TCTA}(5 \mathrm{~nm}) / \mathbf{5 1}(30 \mathrm{~nm}) / \mathrm{TPBi}(30 \mathrm{~nm}) / \mathrm{LiF}$ $(1 \mathrm{~nm}) / \mathrm{Al}(150 \mathrm{~nm})$ 显示出完美色纯度, 其 CIE 的坐标为 $(0.15,0.05)$, 并伴随着极低的启动电压为 $2.7 \mathrm{~V}$, 最大外 量子效率、电流效率和电源效率分别为 $2.74 \% 、 1.28 \mathrm{~cd}$ -
$\mathrm{A}^{-1}$ 和 $1.12 \mathrm{~lm} \cdot \mathrm{W}^{-1}$.

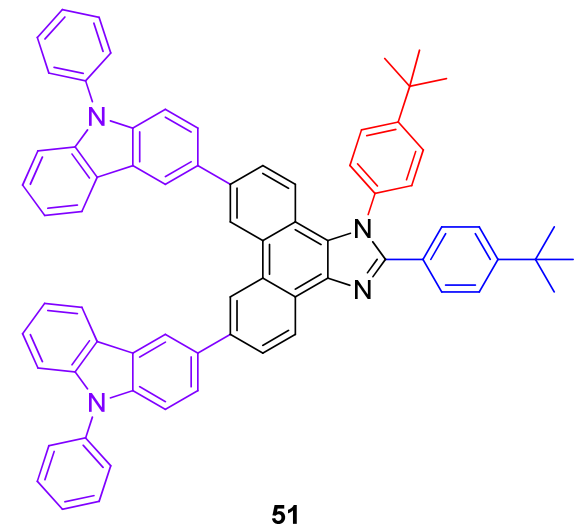

为了避免直接在 $\mathrm{C} 2$ 位置上引入给电子基团, 使其 ICT 现象严重, Lee 等 ${ }^{[94]}$ 在菲并咪唑基团 C6 号位和 C9 号位引入不同的苯衍生物(苯、菜、菲、葱、萠), 合成 了菲并咪唑衍生物 $52 \sim 58$, 研究这两个位置上取代基 的不同及连接方式不同对分子发射光谱的影响，并且通 过理论计算得出 C6 号位取代和 C9 号位取代的电子性 质不同，电子向 C6 位置更容易转移. 荧光测试结果表 明: 取代基的不同大小及共轭程度与其空间位阻对分子 的发射具有决定性的影响, 相比于 C2 位置上的取代 ${ }^{[95]}$, C6 与 C9 位置取代更能实现有效的 $\pi$ 共轭. C6 号位取代 和 C9 号位取代的 57 和 $\mathbf{5 8}$ 比 C2 位置取代分子的发射 光谱更加蓝移，随着取代基苯环个数的上升，当取代基 为葱或萠时, 分子内存在严重的 ICT 现象, 影响其色纯 度及光色，而其他衍生物并没有明显的发射红移. 以上 述分子为 OLED 器件的发光层, 器件结构为 ITO/NPB $(70 \mathrm{~nm}) / \mathrm{TCTA}(5 \mathrm{~nm}) / \mathbf{5 2} \sim \mathbf{5 8}(30 \mathrm{~nm}) / \mathrm{TPBi}(30 \mathrm{~nm}) / \mathrm{LiF}$ $(1 \mathrm{~nm}) / \mathrm{Al}(150 \mathrm{~nm}), \mathbf{5 4}, \mathbf{5 7}$ 和 $\mathbf{5 8}$ 的启动电压很低, 可能 是由于其发光层优秀的电荷传输能力较小及单三线态 能级差. 所有的器件中, $\mathbf{5 8}$ 表现出最好的电致发光性能, 拥有 $5.69 \%$ 的最大外量子效率及 $8.46 \mathrm{~lm} \cdot \mathrm{W}^{-1}$ 的电源效 率, 但是其色坐标 $(0.157,0.177)$ 为天蓝色. 53, 55 和 56 器 件为深蓝色发射, CIE 坐标分别为 $(0.162,0.043),(0.161$, $0.063)$ 和 $(0.158,0.050)$, 对比不修饰分子 $\mathbf{5 2}$ 的器件 $(0.163,0.076)$ 的色标更加深蓝, 其中 $\mathbf{5 6}$ 为发光层的器件 具有 3.72\%的外量子产率, 为上述紫蓝色发射器件的最 优值. 并且, 以 $5 \%$ 质量分数的 $\mathbf{5 6}$ 掺杂在 $\mathrm{CPB}$ 中作为器 件发光层, 色坐标为 $(0.155,0.065)$, 拥有 $5.28 \%$ 的最大 外量子产率, 其效率滚降十分微弱, 表现在高亮度 1000 $\mathrm{cd} \cdot \mathrm{m}^{2}$ 时仍然保持 $5.01 \%$ 的外量子产率, 在 $\mathrm{CIE}_{y}$ 小于 0.08 的器件中效率滚降最小.

\section{3 无 D-T-A 结构的菲并咪唑衍生物}

近年来, 以芳基取代基为共轭桥的菲并咪唑衍生物 


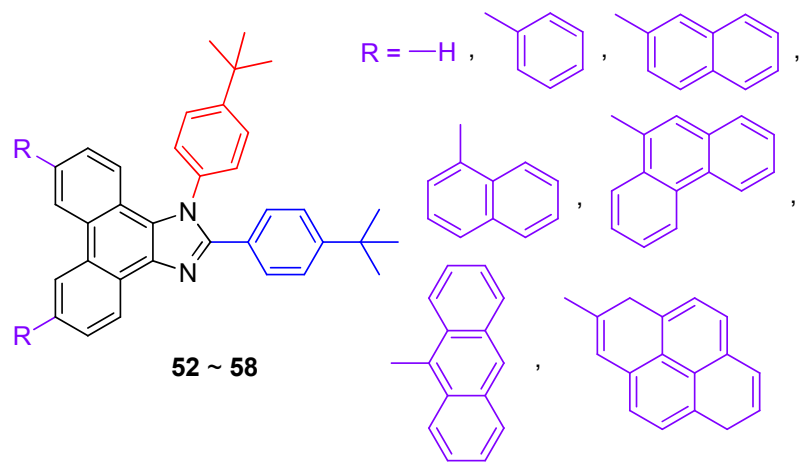

蓝光材料由于具有优秀的色纯度、热稳定性, 良好的苂 光量子产率, 极有潜力的双极性特质, 以及高的激子利 用率(Exciton Utilization Efficiency, EUE), 也受到大家 的关注. 经过不断地尝试和理论计算, 基于 $\mathrm{N} 1$ 及 $\mathrm{C} 2$ 位 置上的取代基衍生物, 由于其性能卓越, 被广泛设计并 运用. $\mathrm{Ma}$ 等 ${ }^{[32]}$ 早年报道的双菲并咪唑分子 59 及三菲并 咪唑分子 60,59 具有优秀的热稳定性及器件性能, 但是 其器件发射远离深蓝发射区(468 nm); 而 60 较 59 发射 蓝移, 但是其升华温度过于接近分解温度, 无法满足真 空蒸镀器件的要求, 限制了它在 OLED 中的运用.

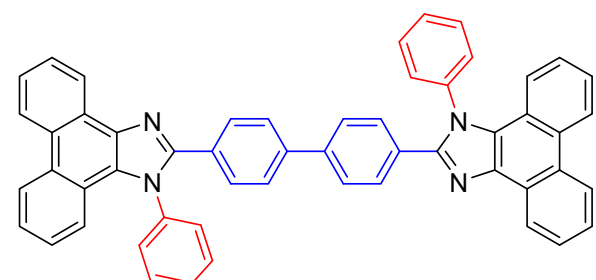

59

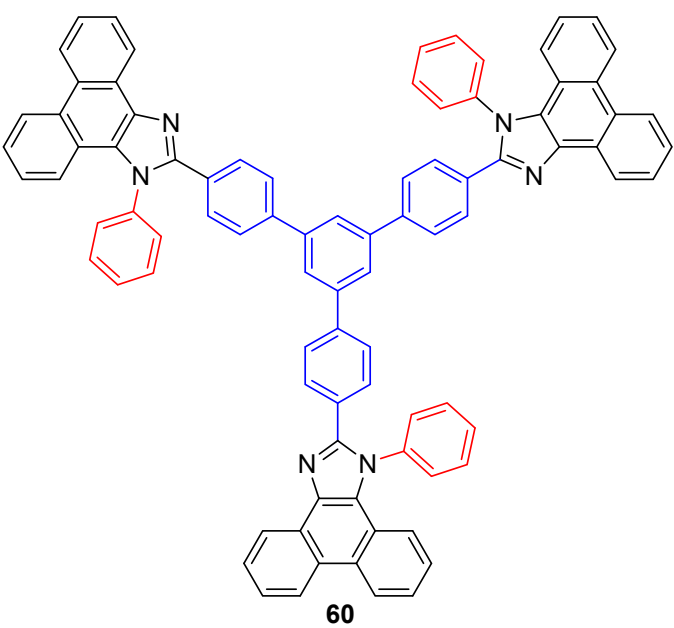

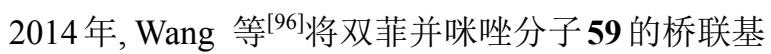
团苯基的连接方式由对位变为间位, 得到单间位取代菲 并咪唑 61 和双间位取代菲并咪唑 62. 通过减少 C2 位置 上的取代方式使其共轭程度降低, 在维持材料热物理性 质的情况下, 有效地调节材料的发光颜色, 薄膜中 61 发 射(433 nm) 和 62 发射(402 nm) 较 59 (468 nm) 有明显蓝 移, 器件中也展示出蓝色发射 $(440 \mathrm{~nm}$ ) 和满足 NTSC 标
准的 CIE 坐标 $(0.16,0.11)$. 但是，由于自身过于扭曲的 结构导致其聚集态结构堆积的不紧密，菲并咪唑的平面 难以形成长程载流子传输通道, 导致其器件启动电压的 上升及电致发光效率的下降.
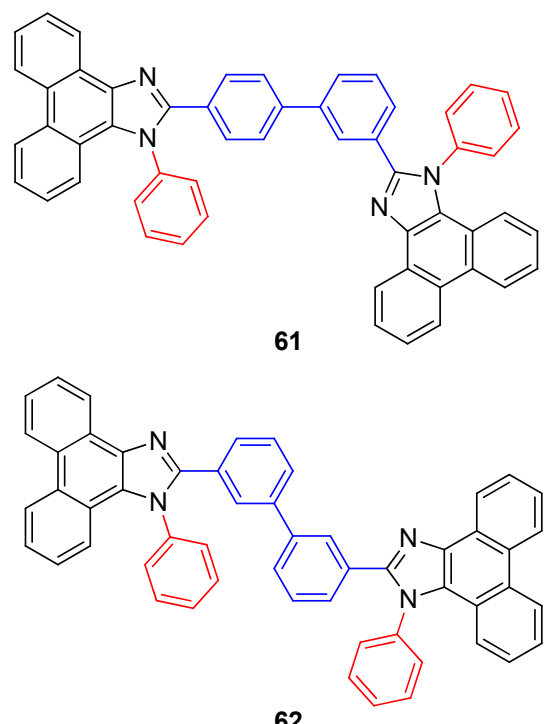

2016 年, Wang 等 ${ }^{[97]}$ 后来改变两个 PPI 之间的连接 方式, 通过引入一个苯环降低其共轭程度, 从而获得更 深蓝发射的分子 63 和 64,63 展现出与 PPI 相近的近紫 外发射及光物理和电化学性质, 及非掺杂的器件中显示 出适宜的 CIE 坐标 $(0.156,0.050)$. 通过在菲并咪唑的 N1 苯环取代基上引入氰基后，不仅加大了分子的热稳定性 并且使其具有双极性，增强了器件的载流子注入及传输 平衡, 从而达到了更好的器件性能, 同时非掺杂的器件 CIE 坐标能维持在 $(0.150,0.080)$, 而且通过 N1 位置上 $\mathrm{CT}$ 态的构建, 使得器件的效率滚降得到有效的抑制, 但是其亮度和外量子效率都不高. 显示出无 D- $\pi-\mathrm{A}$ 结构 的菲并咪唑衍生物自身的局限性.

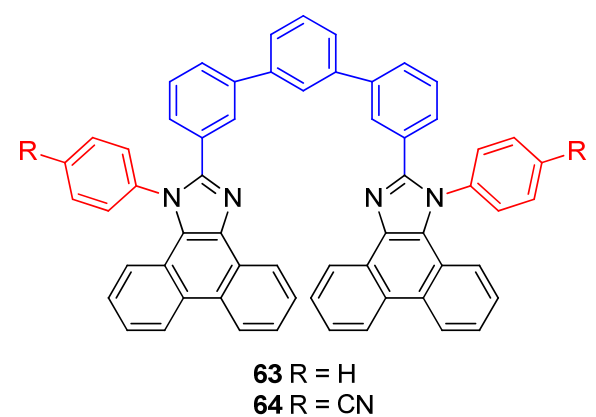

\section{4 总结与展望}

综上所述，菲并咪唑基团由于其自身具有双极性的 特性，易于修饰，合成简单，并且其蓝光衍生物分子设 计可行性高, 价格低廉, 成为制备色纯度高的蓝光材料 
的有效途径. 基于菲并咪唑基团的蓝光材料, 分子设计 由最初传统的荧光分子, 逐渐转化为利用三重态一三重 态湮灭上转换的 TTA 原理的 $\mathrm{p}$ 型延迟苂光材料, 及拥有 LE 态和 CT 态杂化结合的局域杂化电荷转移激发态 (HLCT) 材料, 突破传统苂光材料只有 $25 \%$ 的单线态激 子利用率, 实现了高外量子效率及高色纯度的蓝光材 料. 与此同时, 高效的菲并咪唑蓝光材料在发光主体、 发光客体、光敏剂等各个领域均得到了广泛运用.

尽管如此, 设计高效的菲并咪唑蓝光材料在给受体 与桥联基团的选择、取代基的取代位置、给体与受体之 间 $\pi-\pi$ 共轭长度等方面, 仍然需要进行进一步的优化, 以得到更高的苂光量子产率及更蓝 $\left(\mathrm{CIE}_{x+y}<0.3\right)$ 的发 射, 使器件达到更高的外量子产率及低的效率滚降.

传统荧光材料最大 $5 \%$ 的外量子产率已经成为其发 展的瓶颈, 利用 TTA 原理的 $\mathrm{p}$ 型荧光材料虽然拥有着较 高的外量子产率及微弱的效率滚降, 但是其非掺杂器件 的色纯度往往不尽人意. 拥有 HLCT 的材料具有色纯度 高及效率滚降较低的优点, 但其最大外量子产率还存在 进一步的提升空间.

值得关注的是, 菲并咪唑自身过大的 $\Delta E_{\mathrm{ST}}$, 导致其 构筑热活化延迟苂光材料一直是一个难点, 虽然已有菲 并咪唑的 TADF 分子报道, 但为绿光发射, 具有 TADF 效应的菲并咪唑蓝光材料还未见报道, 如何通过分子设 计实现突破是当下具有挑战性的问题.

与此同时, 为了摆脱传统的真空热蒸镀工艺加工步 骤繁琐, 造价高昂的缺点, 已经有溶液加工的菲并咪唑 材料蓝光材料被报道. 我们课题组也报道了己基取代芴修饰的菲并咪唑化合物 ${ }^{[98]}$, 以其作为发光层构筑了 旋涂的 OLED, 但是其电致发光性能与真空蒸镀 OLED 相比并不是十分理想. 所以如何实现高效的旋涂加工器 件, 以降低 OLED 器件制作成本及减少其工艺流程, 仍 然是一个具有挑战性的问题. 针对蓝光材料宽的 HOMO 和 LUMO 能隙带 $(>3.0 \mathrm{eV})$, 使其为 OLED 器件 有机层时不利于空穴和电子注入的固有属性, 如何开发 更高效的菲并咪唑蓝光材料或设计更合理蓝光器件结 构, 是实现全色显示和固态发光的更进一步发展的突破 口.

\section{References}

[1] Tonzola, C. J.; Kulkarni, A. P.; Gifford, A. P.; Kaminsky, W.; Jenekhe, S. A. Adv. Funct. Mater. 2010, 17, 863.

[2] Forrest, S. R. Nature 2004, 428, 911.

[3] Mitschke, U.; Bäuerle, P. J. Chem. Mater. 2000, 10, 1471.

[4] Wei, B.; Liu, J. Z.; Zhang, Y.; Zhang, J. H.; Peng, H. N.; Fan, H. L.; He, Y. B.; Gao, X. C. Adv. Funct. Mater. 2010, 20, 2448.

[5] Chu, T. Y.; Song, O. K. Appl. Phys. Lett. 2007, 90, 151.

[6] Huang, H.; Wang, Y.; Wang, B.; Zhuang, S.; Pan, B.; Yang, X.; Wang, L.; Yang, C. J. Mater. Chem. C 2013, 1, 5899.

[7] Chien, C. H.; Chen, C. K.; Hsu, F. M.; Shu, C. F.; Chou, P. T.; Lai,
C. H. Adv. Funct. Mater. 2010, 19, 560.

[8] Goushi, K.; Kou, Y.; Sato, K.; Adachi, C. Nat. Photonics 2012, 6, 253.

[9] Lin, M. S.; Chi, L. C.; Chang, H. W.; Huang, Y. H.; Tien, K. C.; Chen, C. C.; Chang, C. H.; Wu, C. C.; Chaskar, A.; Chou, S. H. J. Chem. Mater. 2011, 22, 870.

[10] Chou, H. H.; Cheng, C. H. Adv. Mater. 2010, 22, 2468.

[11] Yook, K. S.; Lee, J. Y. Adv. Mater. 2012, 24, 3169.

[12] Lee, S. J.; Park, J. S.; Yoon, K. J.; Kim, Y. I.; Jin, S. H.; Kang, S. K.; Gal, Y. S.; Kang, S.; Lee, J. Y.; Kang, J. W. Adv. Funct. Mater. 2010, 18, 3922.

[13] Zhao, G.; Liu, Y.; Zhiming, W.; Shen, F.; He, L.; Sun, G.; Liang, Y.; Ying, L.; Ping, L.; Ma, Y. Chemistry. 2013, 19, 2602.

[14] Shih, P. I.; Chuang, C. Y.; Chien, C. H.; Diau, E. W. G.; Shu, C. F. Adv. Funct. Mater. 2010, 17, 3141

[15] Kim, R.; Lee, S.; Kim, K. H.; Lee, Y. J.; Kwon, S. K.; Kim, J. J.; Kim, Y. H. Chem. Commun. 2013, 49, 4664.

[16] Zheng, C. J.; Zhao, W. M.; Wang, Z. Q.; Huang, D.; Ye, J.; Ou, X. M.; Zhang, X. H.; Lee, C. S.; Lee, S. T. J. Chem. Mater. 2010, 20, 1560 .

[17] Moorthy, J. N.; Natarajan, P.; Venkatakrishnan, P.; Huang, D. F.; Chow, T. J. Org. Lett. 2007, 9, 5215.

[18] Tao, S. L.; Peng, Z. K.; Zhang, X. H.; Wang, P. F.; Lee, C. S.; Lee, S. T. Adv. Funct. Mater. 2010, 15, 1716.

[19] Tong, Q. X.; Lai, S. L.; Chan, M. Y.; Zhou, Y. C.; Kwong, H. L.; Lee, C. S.; Lee, S. T. Chem. Mater. 2008, 20, 6310.

[20] Lin, S. L.; Chan, L. H.; Lee, R. H.; Yen, M. Y.; Kuo, W. J.; Chen, C. T.; Jeng, R. J. Adv. Mater. 2008, 20, 3947.

[21] Zhang, Q.; Li, J.; Shizu, K.; Huang, S.; Hirata, S.; Miyazaki, H.; Adachi, C. J. Am. Chem. Soc. 2012, 134, 14706.

[22] Hirata, S.; Sakai, Y.; Masui, K.; Tanaka, H.; Lee, S. Y.; Nomura, H.; Nakamura, N.; Yasumatsu, M.; Nakanotani, H.; Zhang, Q. Nat. Mater. 2015, 14, 330.

[23] Zhang, Y.; Lai, S. L.; Tong, Q. X.; Lo, M. F.; Ng, T. W.; Chan, M. Y.; Wen, Z. C.; He, J.; Jeff, K. S.; Tang, X. L. Chem. Mater. 2012, 24, 61 .

[24] Li, W.; Liu, D.; Shen, F.; Ma, D.; Wang, Z.; Feng, T.; Xu, Y.; Yang, B.; Ma, Y. Adv. Funct. Mater. 2012, 22, 2797.

[25] Zhang, Y.; Lai, S. L.; Tong, Q. X.; Chan, M. Y.; Ng, T. W.; Wen, Z. C.; Zhang, G. Q.; Lee, S. T.; Kwong, H. L.; Lee, C. S. J. Chem. Mater. 2011, 21, 8206.

[26] Huang, H.; Wang, Y.; Zhuang, S.; Yang, X.; Wang, L.; Yang, C. J. Phys. Chem. C 2012, 116, 19458.

[27] Yuan, Y.; Chen, J. X.; Lu, F.; Tong, Q. X.; Yang, Q. D.; Mo, H. W.; Ng, T. W.; Wong, F. L.; Guo, Z. Q.; Ye, J. Chem. Mater. 2013, 25, 4957.

[28] Chen, W. C.; Yuan, Y.; Wu, G. F.; Wei, H. X.; Tang, L.; Tong, Q. X.; Wong, F. L.; Lee, C. S. Adv. Opt. Mater. 2014, 2, 626.

[29] Yuan, Y.; Li, D.; Zhang, X.; Zhao, X.; Liu, Y.; Zhang, J.; Wang, Y. New J. Chem. 2011, 35, 1534.

[30] Richaud, A.; Barba-Behrens, N.; Méndez, F. Org. Lett. 2011, 13, 972.

[31] Duan, L.; Qiao, J.; Sun, Y.; Qiu, Y. Adv. Mater. 2011, 23, 1137.

[32] Wang, Z.; Lu, P.; Chen, S.; Gao, Z.; Shen, F.; Zhang, W.; Xu, Y.; Kwok, H. S.; Ma, Y. J. Chem. Mater. 2011, 21, 5451.

[33] Wang, Z.; Feng, Y.; Zhang, S.; Gao, Y.; Gao, Z.; Chen, Y.; Zhang, X.; Lu, P.; Yang, B.; Chen, P. Phys. Chem. Chem. Phys. 2014, 16 , 20772.

[34] Liang, X.; Wang, Z.; Wang, L.; Hanif, M.; Hu, D.; Su, S.; Xie, Z.; Gao, Y.; Yang, B.; Ma, Y. Chin. J. Chem. 2017, 35.

[35] Chen, W. C.; Tong, Q. X.; Lee, C. S. Sci. Adv. Mater. 2015, 7, 2193.

[36] Jiang, J.; Hu, D.; Hanif, M.; Li, X.; Su, S.; Xie, Z.; Liu, L.; Zhang, S.; Yang, B.; Ma, Y. Adv. Opt. Mater. 2016, 4, 2109.

[37] Gong, S.; Chen, Y.; Luo, J.; Yang, C.; Zhong, C.; Qin, J.; Ma, D. Adv. Funct. Mater. 2011, 21, 1168.

[38] Eakins, G. L.; Alford, J. S.; Tiegs, B. J.; Breyfogle, B. E.; Stearman, C. J. J. Phys. Org. Chem. 2011, 24, 1119. 
[39] Tan, Y.; Zhao, Z.; Shang, L.; Liu, Y.; Wei, C.; Li, J.; Wei, H.; Liu, Z.; Bian, Z.; Huang, C. J. Mater. Chem. C 2017, 5, 11901.

[40] Li, W.; Pan, Y.; Xiao, R.; Peng, Q.; Zhang, S.; Ma, D.; Li, F.; Shen, F.; Wang, Y.; Yang, B. Adv. Funct. Mater. 2014, 24, 1609.

[41] Wang, Q.; Ma, D. Chem. Soc. Rev. 2010, 39, 2387.

[42] Zhang, S.; Li, W.; Yao, L.; Pan, Y.; Shen, F.; Xiao, R.; Yang, B.; Ma, Y. Chem. Commun. 2013, 49, 11302.

[43] Zhang, S.; Yao, L.; Peng, Q.; Li, W.; Pan, Y.; Xiao, R.; Gao, Y.; Gu, C.; Wang, Z.; Lu, P.; Li, F.; Su, S.; Yang, B.; Ma, Y. Adv. Funct. Mater. 2015, 25, 1755.

[44] Liu, B.; Yuan, Y.; He, D.; Huang, D. Y.; Luo, C. Y.; Zhu, Z. L.; Lu, F.; Tong, Q. X.; Lee, C. S. Chemistry 2016, 22, 12130.

[45] Chen, W. C.; Yuan, Y.; Ni, S. F.; Tong, Q. X.; Wong, F. L.; Lee, C. S. Chem. Sci. 2017, 8, 3599.

[46] Liu, B.; Yu, Z. W.; He, D.; Zhu, Z. L.; Zheng, J.; Yu, Y. D.; Xie, W. F.; Tong, Q. X.; Lee, C.-S. J. Mater. Chem. C 2017, 5, 5402.

[47] Wang, Z. Y.; Liu, B.; Zhao, J. W.; Ruan, G. L.; Tao, S. L.; Tong, Q. X. Org. Electron. 2018, 52, 89.

[48] Chen, W. C.; Yuan, Y.; Zhu, Z. L.; Jiang, Z. Q.; Liao, L. S.; Lee, C. S. Adv. Opt. Mater. 2018, 6, 1700855.

[49] Zhu, Z. L.; Ni, S. F.; Chen, W.; Chen, M.; Zhu, J.; Yuan, Y.; Tong, Q. X.; Wong, F. L.; Lee, C. J. Mater. Chem. C 2018, 6, 3584.

[50] Zhao, J.; Liu, B.; Wang, Z.; Tong, Q. X.; Du, X.; Zheng, C. J.; Lin, H.; Tao, S. L.; Zhang, X. H. ACS Appl. Mater. Interfaces 2018, 10, 9629.

[51] Sinha, S.; Rothe, C.; Güntner, R.; Scherf, U.; Monkman, A. P. Phys. Rev. Lett. 2003, 90, 127402.

[52] Chiang, C. J.; Kimyonok, A.; Etherington, M. K.; Griffiths, G. C.; Jankus, V.; Turksoy, F.; Monkman, A. P. Adv. Funct. Mater. 2013, 23,739 .

[53] Kido, J.; Iizumi, Y. Appl. Phys. Lett. 1998, 73, 2721.

[54] Kondakov, D. Y.; Pawlik, T. D.; Hatwar, T. K.; Spindler, J. P. J. Appl. Phys. 2009, 106, 30.

[55] Chen, Y. H.; Lin, C. C.; Huang, M. J.; Hung, K.; Wu, Y. C.; Lin, W. C.; Chencheng, R. W.; Lin, H. W.; Cheng, C. H. Chem. Sci. 2016, 7, 4044.

[56] Chou, P. Y.; Chou, H. H.; Chen, Y. H.; Su, T. H.; Liao, C. Y.; Lin, H. W.; Lin, W. C.; Yen, H. Y.; Chen, I. C.; Cheng, C. H. Chem. Commun. 2014, 50, 6869 .

[57] Zhang, D.; Zhang, D.; Duan, L. ACS Appl. Mater. Interfaces 2016, 8, 23197.

[58] Kim, B.; Park, Y.; Lee, J.; Yokoyama, D.; Lee, J. H.; Kido, J.; Park, J. J. Mater. Chem C 2012, 1, 432

[59] Shan, T.; Gao, Z.; Tang, X.; He, X.; Gao, Y.; Li, J.; Sun, X.; Liu, Y.; Liu, H.; Yang, B.; Lu, P.; Ma, Y. Dyes Pigm. 2017, 142, 189.

[60] Tang, X.; Bai, Q.; Shan, T.; Li, J.; Gao, Y.; Liu, F.; Liu, H.; Peng, Q.; Yang, B.; Li, F.;Lu, P. Adv. Funct. Mater. 2018, 28, 11.

[61] Baldo, M. A.; O'Brien, D. F.; Thompson, M. E.; Forrest, S. R. Phys. Rev. $B$ 1999, 60, 14422.

[62] Tan, J. H.; Huo, Y. P.; Cai, N.; Ji, S, M.; Li, Z. Z.; Zhang, L. Chin. J. Org. Chem. 2017, 37, 2457 (in Chinese). (谭继华, 霍延平, 蔡宁, 籍少敏, 李宗植, 张力, 有机化学, 2017, 37, 2457.)

[63] Endo, A.; Mai, O.; Takahashi, A.; Yokoyama, D.; Kato, Y.; Adachi, C. Adv. Mater. 2010, 21, 4802

[64] Uoyama, H.; Goushi, K.; Shizu, K.; Nomura, H.; Adachi, C. Nature 2012, 492, 234.

[65] Hirata, S.; Sakai, Y.; Masui, K.; Tanaka, H.; Lee, S. Y.; Nomura, H.; Nakamura, N.; Mao, Y.; Nakanotani, H.; Zhang, Q. Nat. Mater. 2015, 14, 330 .

[66] Huang, Z.; Xiang, S.; Zhang, Q.; Lv, X.; Ye, S.; Guo, R.; Wang, L. J. Mater. Chem. C 2018, 6, 2379.

[67] Pei, Q.; Yang, Y.; Yu, G.; Zhang, C.; Heeger, A. J. J. Am. Chem. Soc. 1996, 118, 3922.

[68] Matyba, P.; Yamaguchi, H.; Chhowalla, M.; Robinson, N. D.; Edman, L. ACS Nano. 2011, 5, 574 .

[69] Pertegás, A.; Tordera, D.; Serrano-Pérez, J. J.; Ortí, E.; Bolink, H. J.
J. Am. Chem. Soc. 2013, 135, 18008.

[70] Subeesh, M. S.; Shanmugasundaram, K.; Sunesh, C. D.; Won, Y. S.; Choe, Y. J. Mater. Chem. C 2015, 3, 4683.

[71] Subeesh, M. S.; Shanmugasundaram, K.; Sunesh, C. D.; Chitumalla, R. K.; Jang, J.; Choe, Y. J. Phys. Chem. C 2016, 120 , 12207.

[72] Subeesh, M. S.; Shanmugasundaram, K.; Sunesh, C. D.; Nguyen, T. P.; Choe, Y. J. Phys. Chem. C 2015, 119, 23676.

[73] Subeesh, M. S.; Nguyen, T. P.; Choe, Y. J. Phys. Chem. C 2017, $121,14811$.

[74] Zhao, G. S.; Shi, C. X.; Guo, Z. Q.; Zhu, W. H.; Zhu, S. Q. Chin. J. Org. Chem. 2012, 32, 1620 (in Chinese).

(赵国生，史川兴，郭志前，朱为宏，朱世琴，有机化学，2012, 32,1620 .)

[75] Li, Z. Z.; Huo, Y. P.; Yang, X. H.; Ji, S. M. Chin. J. Org. Chem. 2016, 36, 2317 (in Chinese). (李宗植, 霍延平, 阳香华, 籍少敏, 有机化学, 2016, 36, 2317.)

[76] Cai, Y.; Du, L.; Samedov, K.; Gu, X.; Fei, Q. I.; Sung, H. H.; Patrick, B. O.; Yan, Z.; Jiang, X.; Zhang, H. Chem. Sci. 2018, 9, 4662.

[77] Qiu, S. H.; Xu, S. J.; Zhou, G. F.; Shui, L. L.; Zhu, X. Z. Chin. J. Org. Chem. 2015, 35, 1746 (in Chinese).

(邱淑海, 许胜杰, 周国富, 水玲玲, 朱晓张, 有机化学, 2015, 35, 1746.)

[78] Song, M.; Chen, Z.; Yu, G. B.; Yin, J.; Liu, S. H. Chin. J. Org. Chem. 2015, 35, 681 (in Chinese). (宋敏, 陈钊, 余广鳌, 尹军, 刘盛华, 有机化学, 2015, 35, 681.)

[79] Jadhav, T.; Choi, J. M.; Shinde, J.; Lee, J. Y.; Misra, R. J. Mater. Chem. C 2017, 5, 6014.

[80] Ekbote, A.; Han, S. H.; Jadhav, T.; Mobin, S. M.; Lee, J. Y.; Misra, R. J. Mater. Chem. C 2018, 6, 2077.

[81] Xie, Z.; Chen, C.; Xu, S.; Li, J.; Zhang, Y.; Liu, S.; Xu, J.; Chi, Z. Angew. Chem., Int. Ed. 2015, 127, 7181.

[82] Xu, S.; Liu, T.; Mu, Y.; Wang, Y. F.; Chi, Z.; Lo, C. C.; Liu, S.; Zhang, Y.; Lien, A.; Xu, J. Angew. Chem., Int. Ed. 2015, 54, 874.

[83] Li, G.; Zhao, J.; Zhang, D.; Shi, Z.; Zhu, Z.; Song, H. Q.; Zhu, J.; Tao, S. L.; Lu, F.; Tong, Q. X. J. Mater. Chem. C 2016, 4, 8787.

[84] Fleetham, T.; Li, G.; Wen, L.; Li, J. Adv. Mater. 2014, 26, 7116.

[85] Zhang, C.; Ji, K.; Wang, X.; Wu, H.; Liu, C. Chem. Commun. 2015, 51,8173 .

[86] Dou, C.; Han, L.; Zhao, S.; Zhang, H.; Wang, Y. J. Phys. Chem. Lett. 2011, 2, 666.

[87] Karabunarliev, S.; Baumgarten, M.; Tyutyulkov, N.; Muellen, K. J. Phy. Chem. 1994, 98, 11892.

[88] Romain, M.; Tondelier, D.; Vanel, J. C.; Geffroy, B.; Jeannin, O.; Raultberthelot, J.; Métivier, R.; Poriel, C. Angew. Chem. Int. Ed. 2013, 125, 14397.

[89] Romain, M.; Thiery, S.; Shirinskaya, A.; Declairieux, C.; Tondelier, D.; Geffroy, B.; Jeannin, O.; Rault-Berthelot, J.; Métivier, R.; Poriel, C. Angew. Chem. Int. Ed. 2015, 54, 1176.

[90] Jing, H.; Ning, S.; Dong, Y.; Tang, R.; Ping, L.; Ping, C.; Li, Q.; Ma, D.; Qin, J.; Zhen, L. Adv. Funct. Mater. 2013, 23, 2329.

[91] Zhu, Z. L.; Chen, W. C.; Zhang, L. D.; Liu, X. L.; Tong, Q. X.; Wong, F. L.; Lu, F.; Lee, C. S. J. Mater. Chem. C 2016, 26, 6249

[92] Du, X.; Li, G.; Zhao, J.; Tao, S.; Zheng, C.; Lin, H.; Tong, Q.; Zhang, X. Adv. Opt. Mater. 2017, 5, 23.

[93] He, D.; Yuan, Y.; Liu, B.; Huang, D. Y.; Luo, C. Y.; Lu, F.; Tong, Q. X.; Lee, C. S. Dyes Pigm. 2017, 136, 347.

[94] Chen, W. C.; Yuan, Y.; Xiong, Y.; Rogach, A. L.; Tong, Q. X.; Lee, C. S. ACS Appl Mater Interfaces. 2017, 9, 26268.

[95] Zhang, F.; Li, W.; Wei, D.; Wei, X.; Li, Z.; Zhang, S.; Li, S.; Wei, B.; Cao, G.; Zhai, B. RSC Adv. 2016, 6, 60264.

[96] Wang, Z.; Feng, Y.; Li, H.; Gao, Z.; Zhang, X.; Lu, P.; Chen, P.; Ma, Y.; Liu, S. Phys. Chem. Chem. Phys. 2014, 16, 10837.

[97] Wang, Z.; Li, X.; Xue, K.; Li, H.; Zhang, X.; Liu, Y.; Yu, Z. Q.; Lu, P.; Chen, P. J. Mater. Chem. C 2016, 4, 1886.

[98] Huo, Y. P.; Tan, J. H.; Zhou, P. Q.; Chen, G. W.; Su, S. J.; Cai, X. Y.; CN 108148001, 2018. 